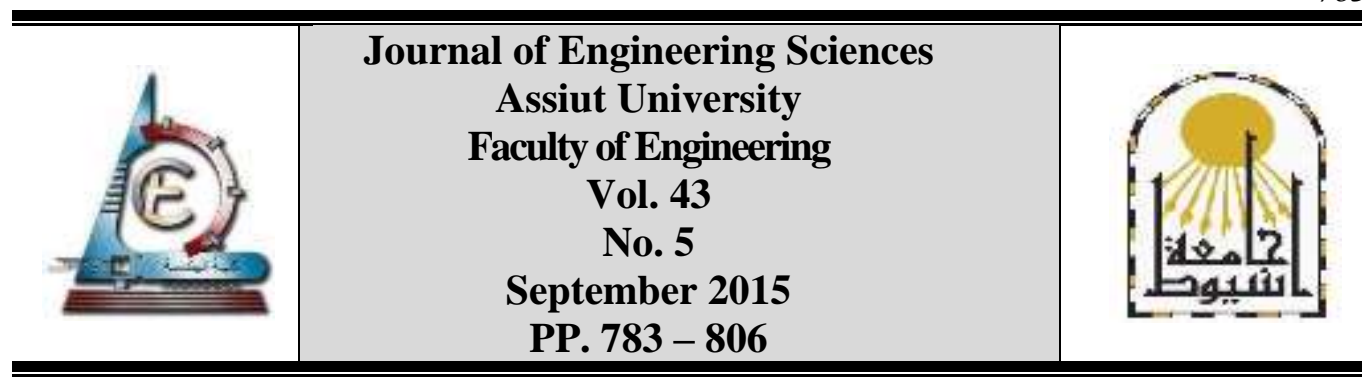

$$
\begin{aligned}
& \text { خصائص وسمات العمارة الديناميكية ـ البعد الرابع في العمارة ـ الزمن } \\
& \text { أحسمد محسمود صـابر محــمد }
\end{aligned}
$$

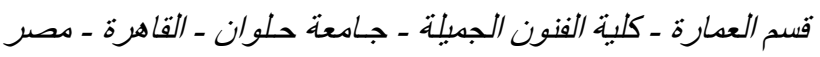

(Received 13 July 2015; Revised 10 August 2015; Accepted 18 August 2015)

$$
\text { ملخص البحث }
$$

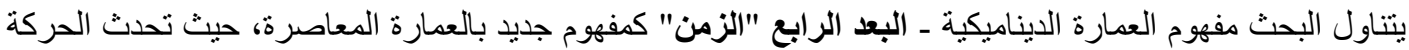

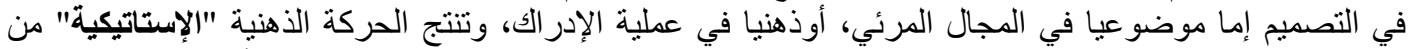

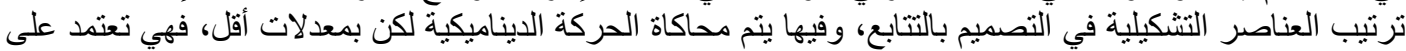

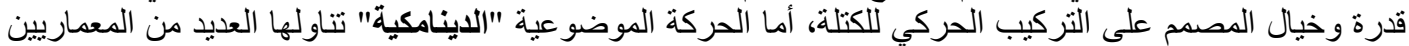

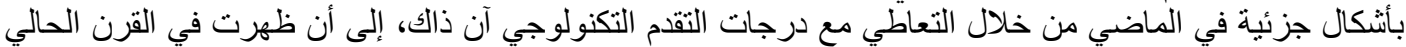

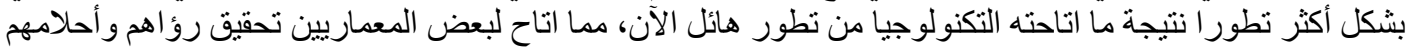

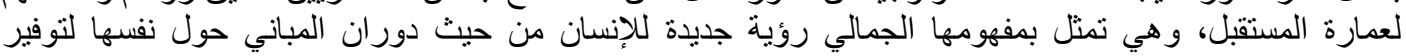

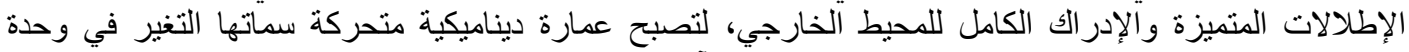

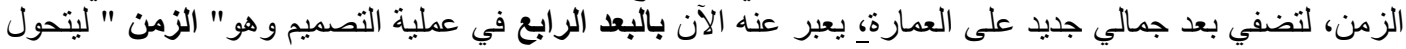

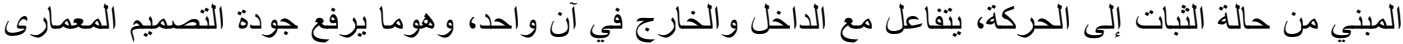

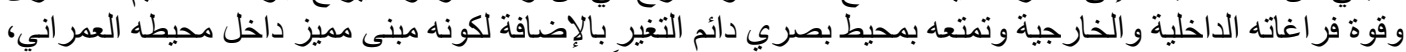

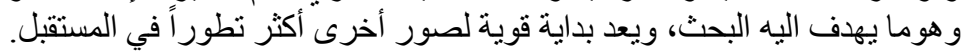

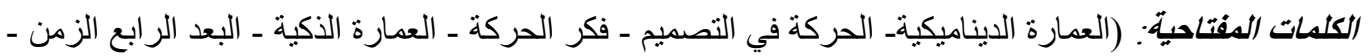

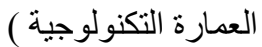

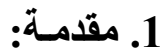

إن النماذج المعمارية الحالية والمتو ارثنة من العصور السابقة توحى أن هناك ثمة علاقة مثبتة ما بين التطور

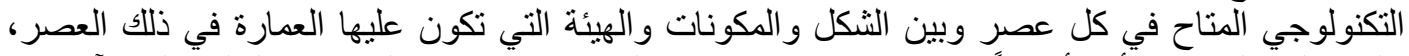

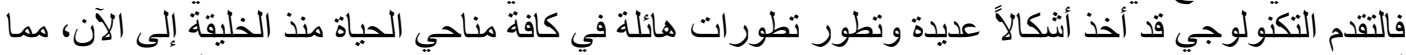

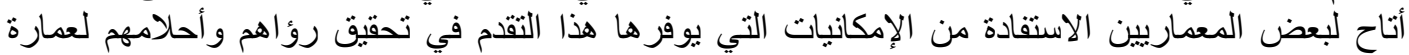

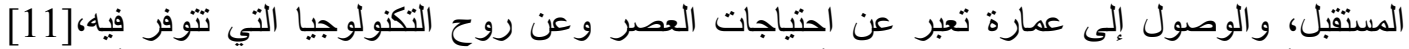

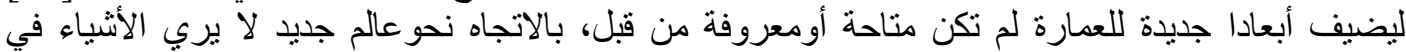

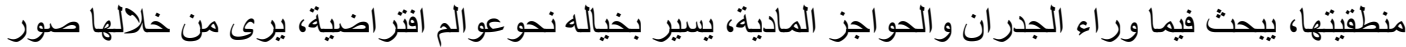

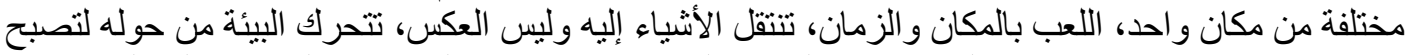

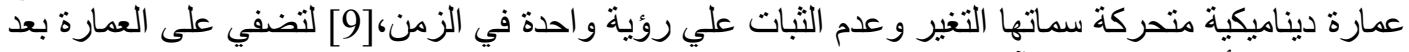

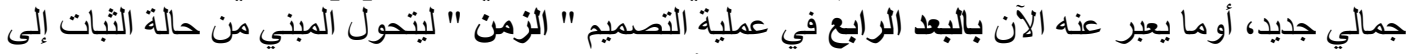

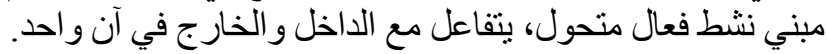




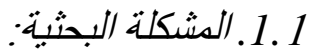

عملية التغير والتحول في العمارة، لكي تكون سلمية غير عشوائية، بتطلاب توافقها مع التغيرات

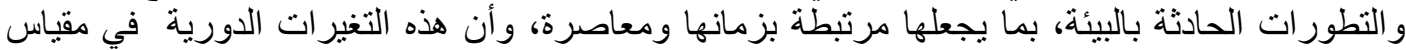

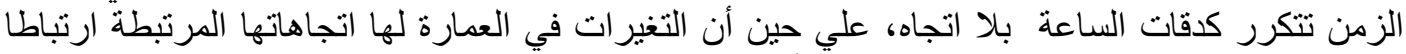

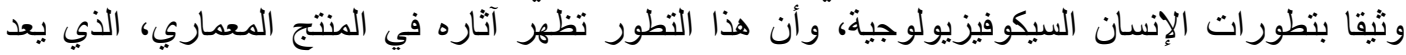
ترجمة حقيقية لهذا التطور ، ويحاول البحث الإجابة علي :

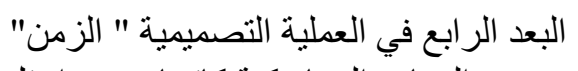

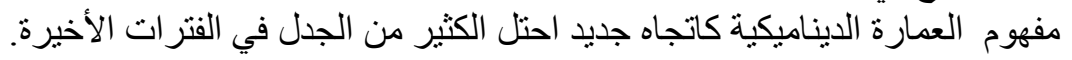

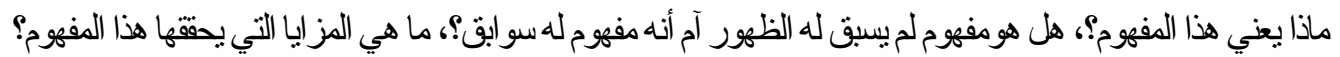

$$
\begin{aligned}
& \text { إمكانيات التطبيق، بين الرفض و القبول و الإتاحة و القيود؟ } \\
& \text { كا } 2.1 \text { أهمية البحث: }
\end{aligned}
$$

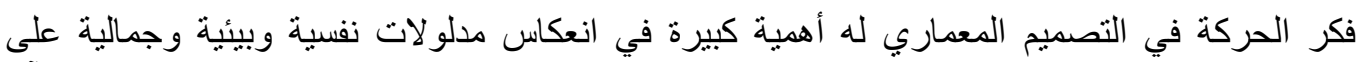

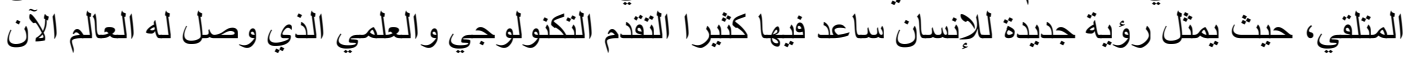

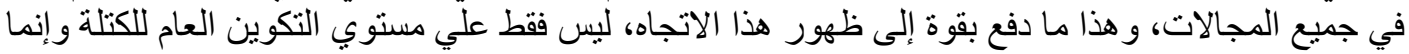

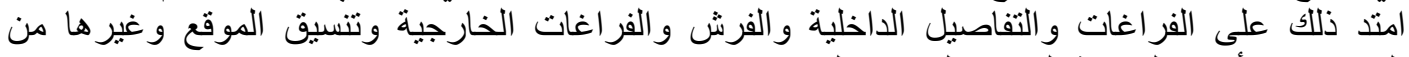

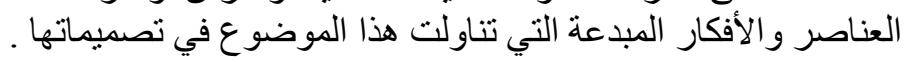

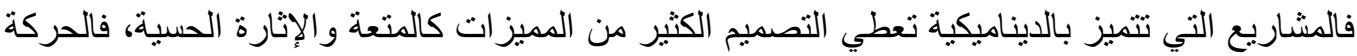

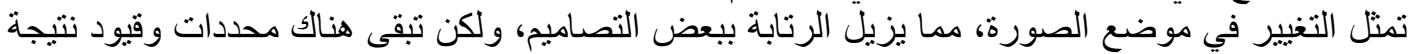
التكلفة وتقنيات التنفيذ العالية، لكنها في النهاية لا تقف حائل أمام إمكانية تطبيقه.

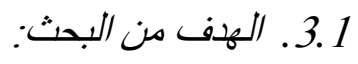

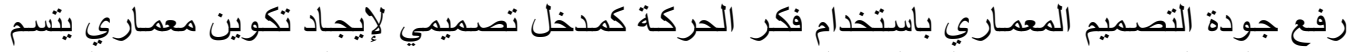

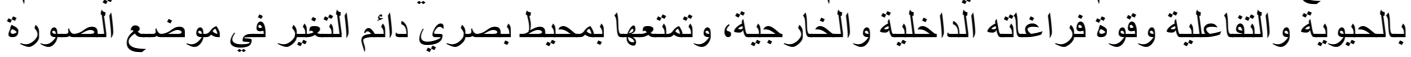

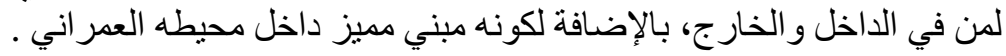

$$
\text { 4.1 }
$$

$$
\text { يعتمد البحث على عدة مناهج بحثية وهي: }
$$

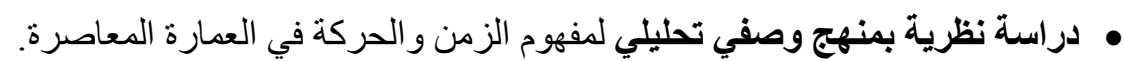

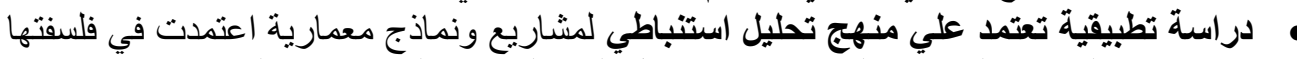

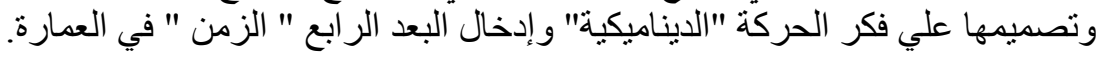

$$
\text { 5.1. الفرضية البحثية: }
$$

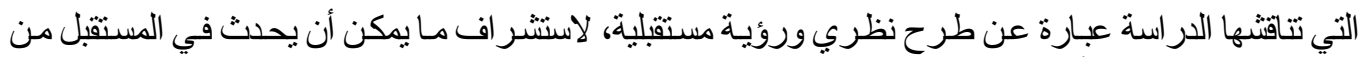

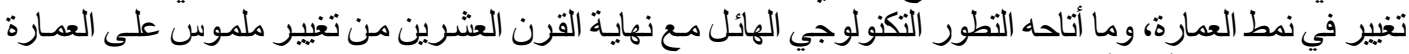

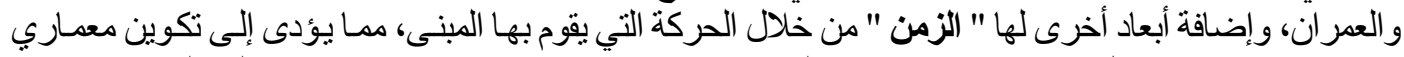

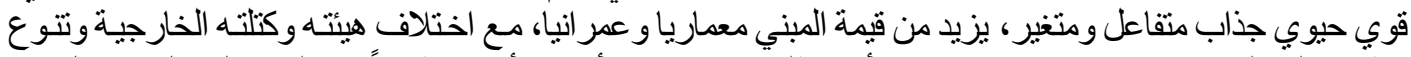

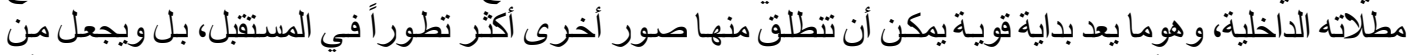

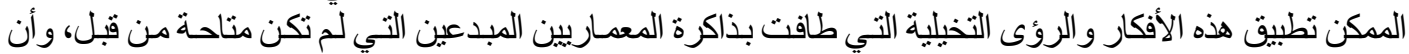
التطور الحادث مع بداية القرن الحادي والعشرين، سيغير شكل ونمط الحياة و العمران بالمدينة: 
أحسد محسمود صـابر محسـد، خصائص وسعات العمارة الدبناميكية ـ البعد الرابع في العمارة ـ الزمن

\section{2. مفهوم الزمن في العملية التصميمية:}

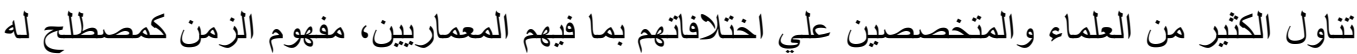

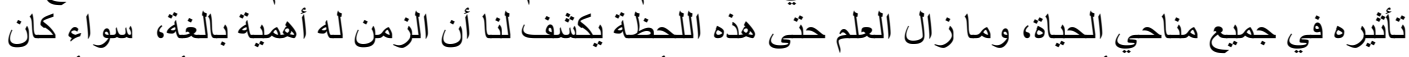

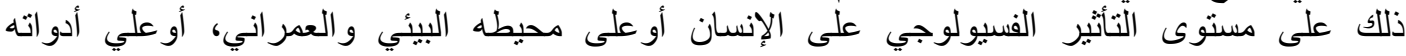

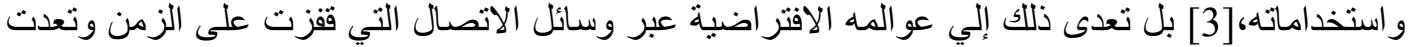
الحدود وتخطت المسافات، و هذا يوجب علينا فهم تأثير الزمن في عالمنا بالأخص في العمارة و العدران.

$$
1.2 \text { ـ مفهوم الزمن كمصطلح أوجده الإنسان: }
$$

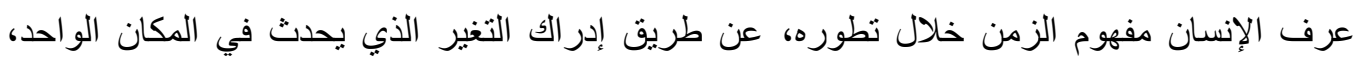
و هويتوقف علي الذكريات المتصورة عقليا، و أبرز هذه التغير ات بالنسبة لمفهوم الزئن من لدي الإنسان اثنان :

الأول: هو التغيير الفسيولوجي الذي يحسه ويلاحظه الفرد في جسمه، أي العجز أوكبر السن.[4] الثاني: التغيير الدوري يلاحظه الإنسان بحركة الكون، الثمس والقمر والكواكب، ولهذين النوعين الهين أهمية

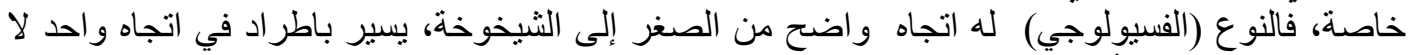

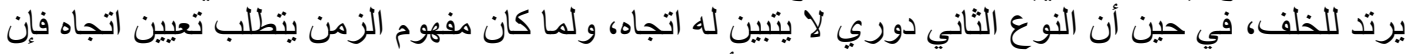

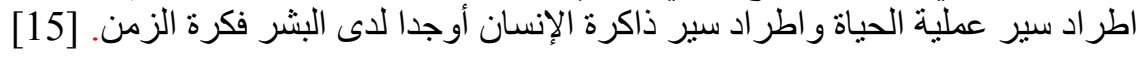

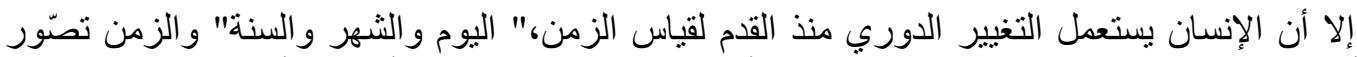

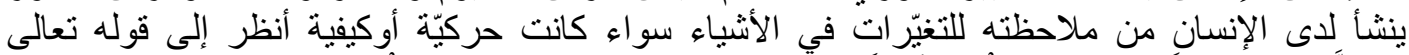

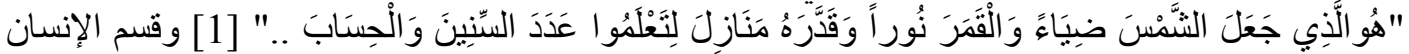

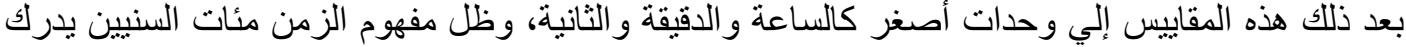

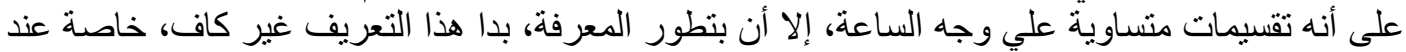

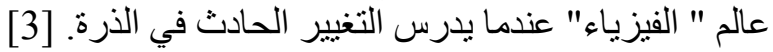

ويقول حسن فتحي عن مفهوم الزمن : هو الفترة بين حدثين بالنسبة لنقطة ثنابتة، إما بتعدد الصور المتعاقبة،

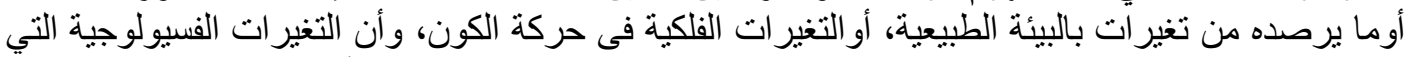

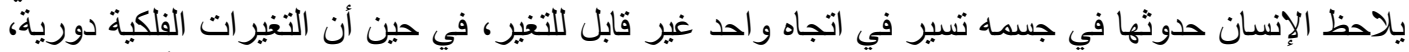

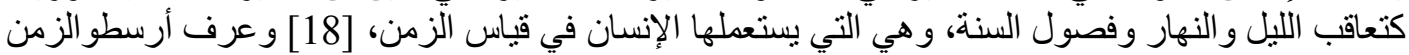
بأن : "الزمن هوالحركة " حيث اتفق الكثير من العلماء على هذا التعريف.

هذا التلخيص السريع لتعريف الزمن، يوضح لنا أن مفهومه ليس بالبساطة التي يبدو عليها، و أنه بتطلب التبا. إعمال الفكر ، لكي يأخذ مكانه في الصورة المتكاملة لحركة تطور الكون والعمر ان الذي لهي لهو أداة نشكيله.

$$
1.1 .2 \text { ـ مفهوم الزمن في العهود التاريخية: }
$$

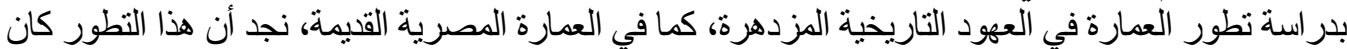

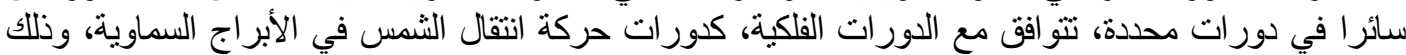

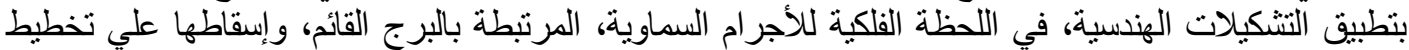
المعبد الذي يرمز لهذا البرج، ويردد صداه على الأرض، وكأنه الوتر المشدود بين السماء و الأرض. [21]

$$
\text { 2.1.2. تطور مفهوم الزمن في الحياة المعاصرة (الفبيتوثانية): }
$$

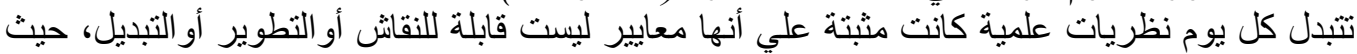

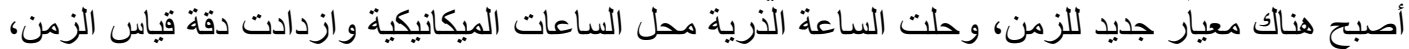

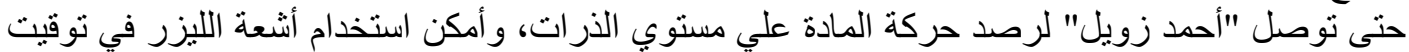
الفيمنوثانية من الوصول إلى كامير ا فائقة السر عة لرصد الرداد حركة المادة علي مستوي الذرات. [24] 


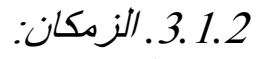

مصطلح فيزيائي منحوت من كلمني الزمان والمكان (Space-time) لتعبر عن الفضـاء رباء رباعي الأبعاد

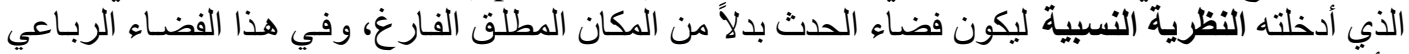

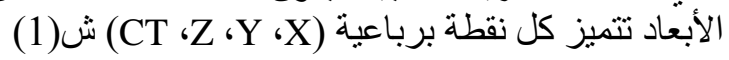

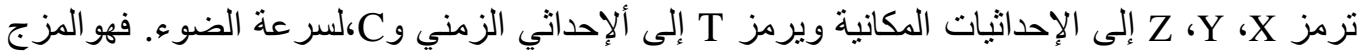

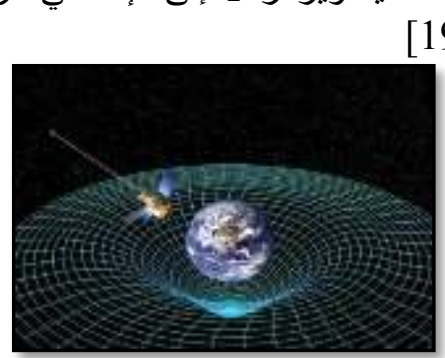

شكل (1): انحناء الزمكان، أحد الأقمار الصناعية يدور في مجال جاذبية الأرض. كما تدور الأرض حول الشمس

في مجال جاذبيتها [126)

وظهرت هذه الأطروحة بواسطة ألبرت أينشتاين في نموذجه النسبي الخاص، لتحدد مكان جسم في لألاني

الفضاء بطريقة أكثر دقة، بالاعتماد على عنصر الزمان بدلا من الاعتماد على الثلاثنة محاور للمكان فقط.

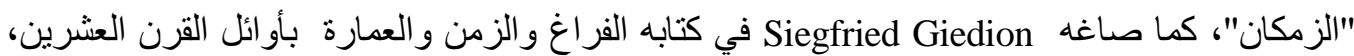

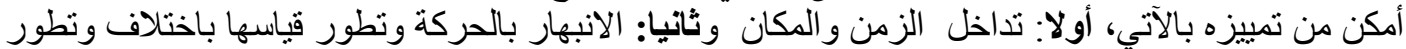

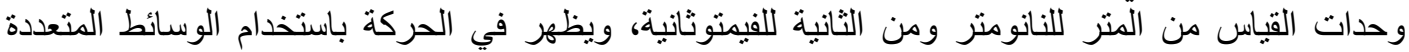

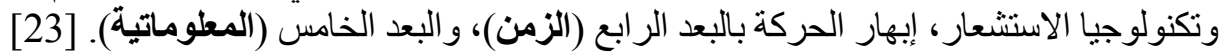

$$
\text { 4.1.2. مفهوم الزمن و المعاصرة: }
$$

يقول حسن فتحي عن المعاصرة، إن عملية التغير و التحول في العمارة لكي تكون سلمية غير عثوائية، بتطلب

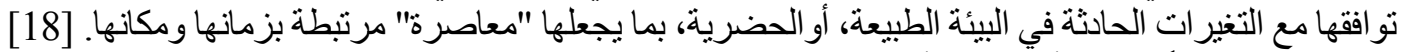

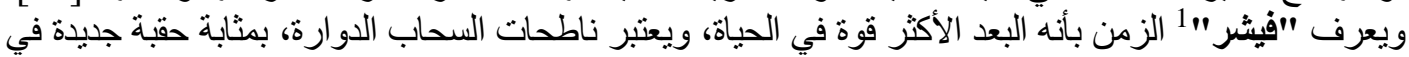

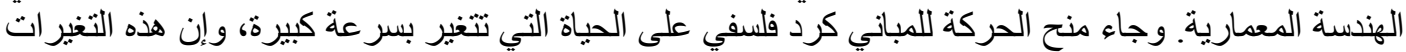

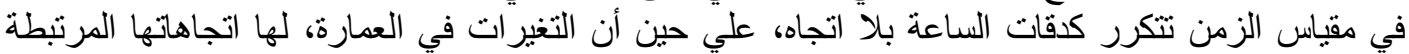
ارتباطاوثيقا بتطورات الإنسان السيكوفيزيولوجية، وإن هذا التطور تظهر آثناره في المنتج المعماري.

\section{3. مفهوم الحركة:}

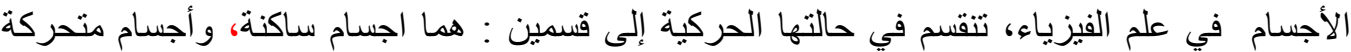

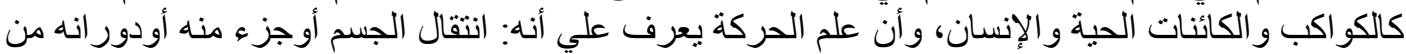

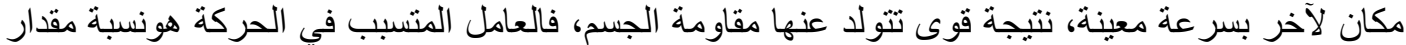

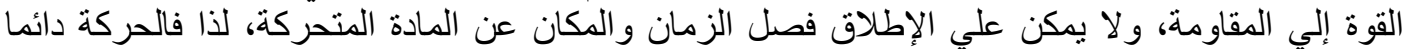

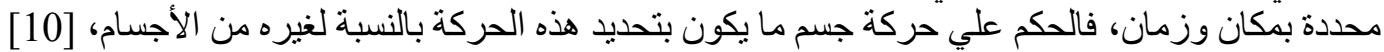

1 بدأ ديفيد فيشر حياته المهنية في فلورنسا بعد ما تخرج من كلية الهندسة المعمارية (رمز عصر النهضة الإيطالية)، قام بالتدريس في نفس النها

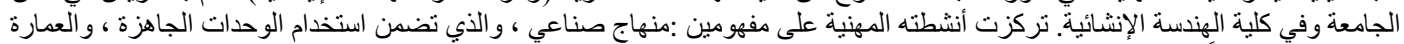

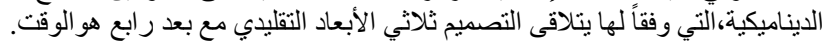


أحسد محسمود صسابر محسـد، خصائص وسعات العمارة الدبناميكية ـ البعد الرابع في العمارة ـ الزمن

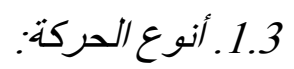

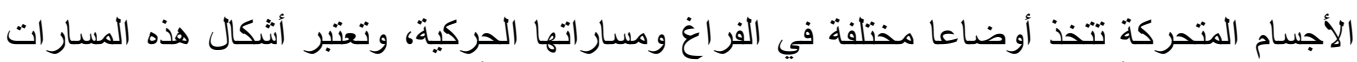

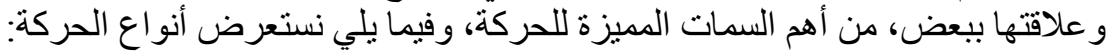

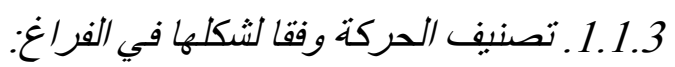

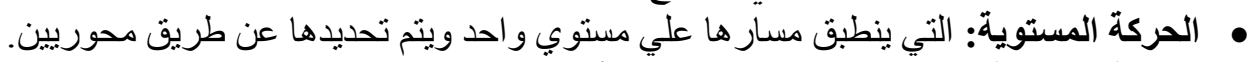

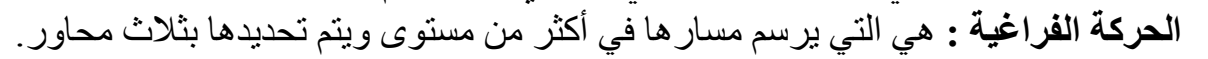

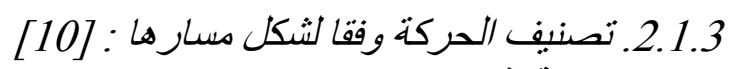

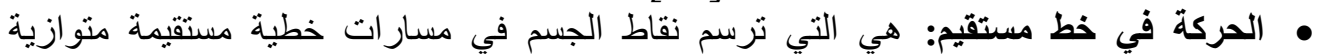

ومتطابقة، وتسمي بالحركة الانتقالية.

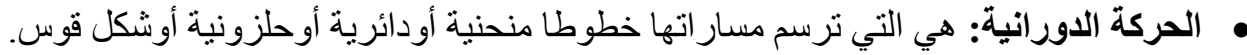

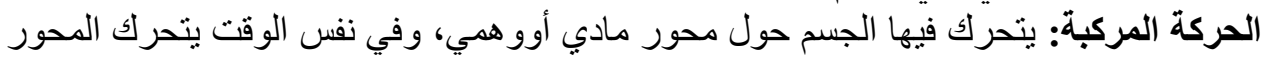
حركة انتقالية في خط مستقيم.

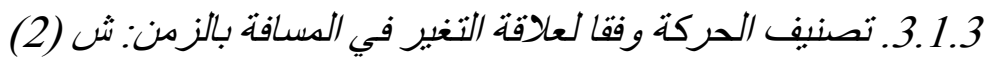

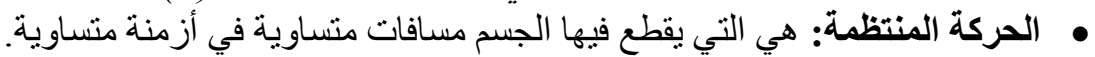

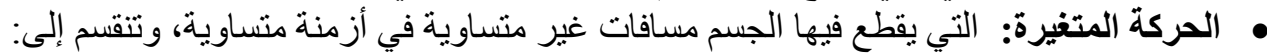

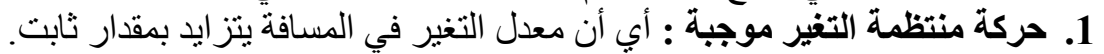

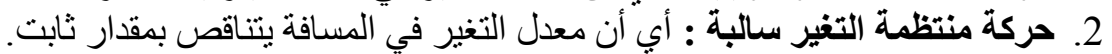
3. حركة غير منتظمة التغير موجبة: أب أن معدل التغير في المسافة يتز ايد بمقدار غير ثابت التيت.
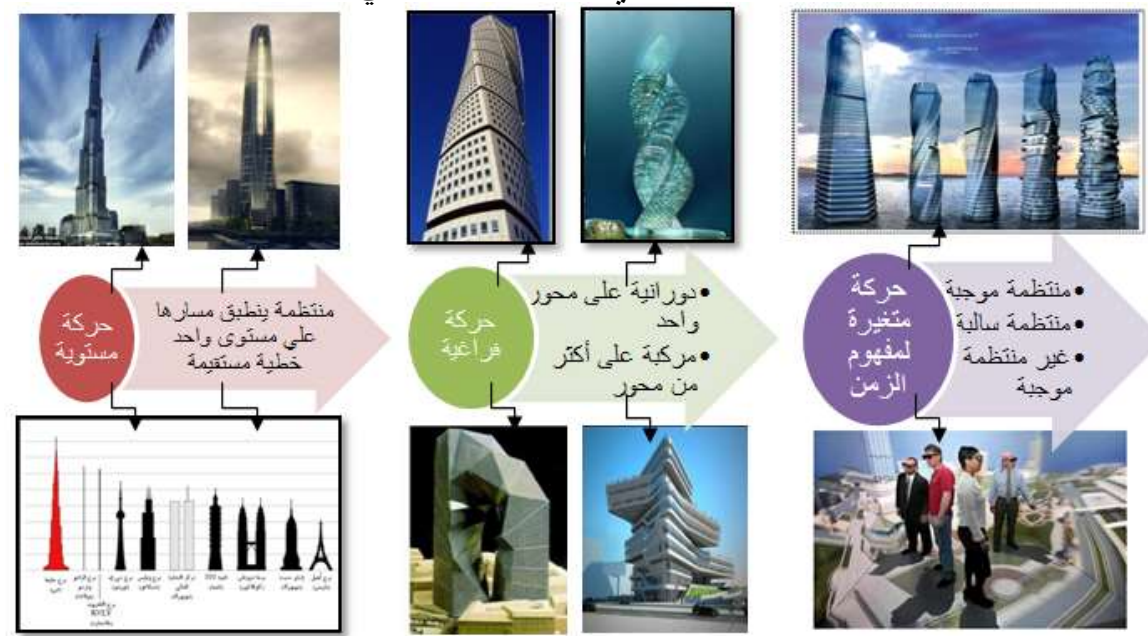

شكل (2): تطور فكر الحركة بالنسبة لمفهوم الزمن، من حركة استاتيكية معدل التغير فيها صفر وصو لا إلي حركة

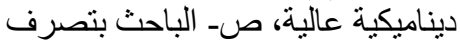

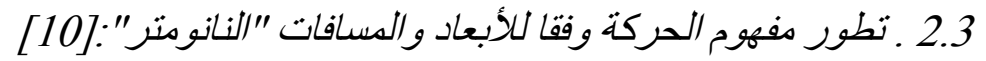

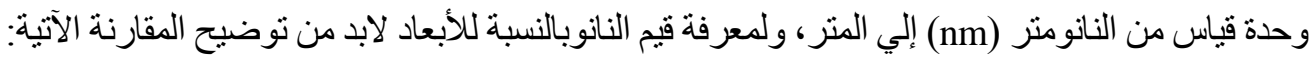

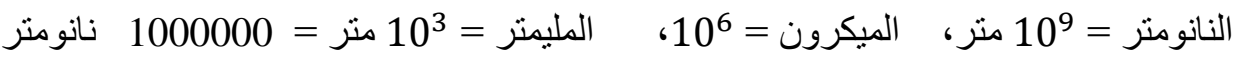

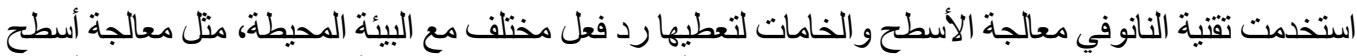

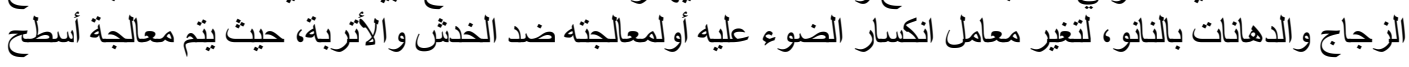


دهانات المبني الخارجية لتصبح ذاتية التظظف باستخدام تقنية النانو، وما تسمي Self-cleaning paint، كما لها

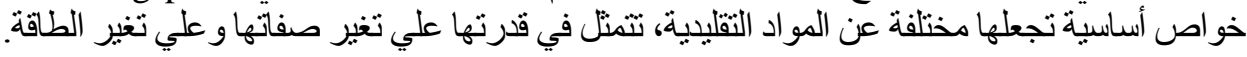

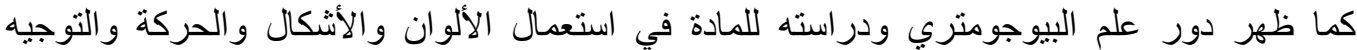

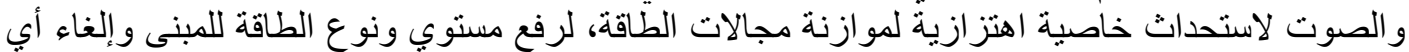

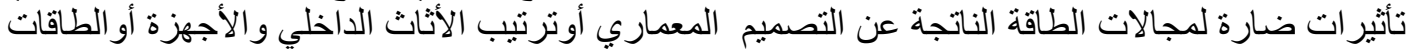

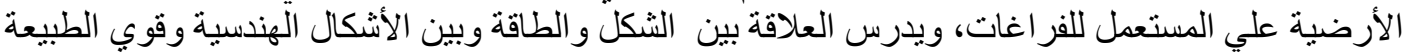

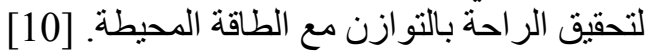
3.3. تطـور مفهوم الحركة وفقا للزمن:

اثبت اينشتين أن الزمن هو البعد الرابع في الكون، حيث طور نظرية النسبية التي تقول : " بأن كل حركة

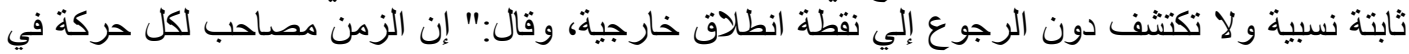

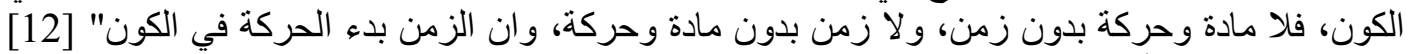

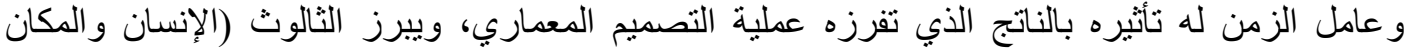

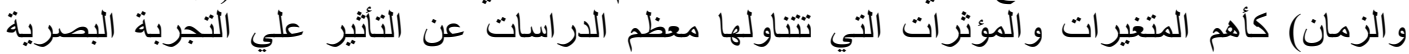

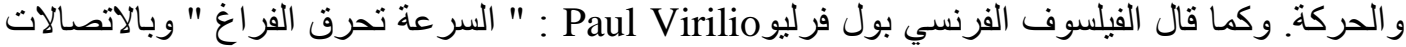

السريعة وصل العصر الحديث إلى السر عة المطلقة، كل شيء حي ومباثر في الزمن الحقيقي" [20]

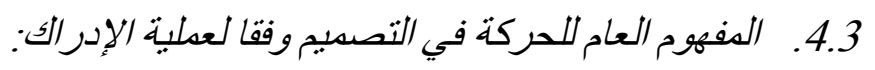

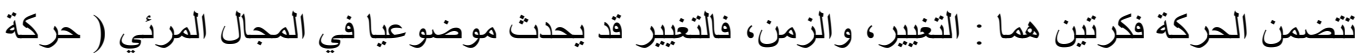

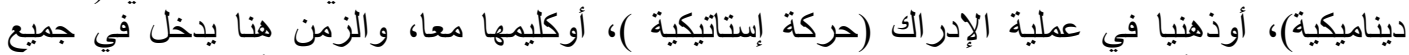

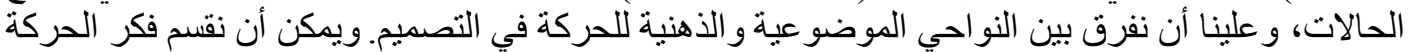

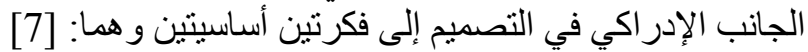

الحركة الذهنية في عملية الإدراك أوما يعرف ( الحركة الإستاتيكية ).

الحركة الموضو عية في المجال المرئي ( الحركة الدينة الديناميكية ).

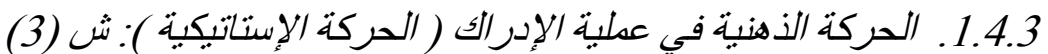

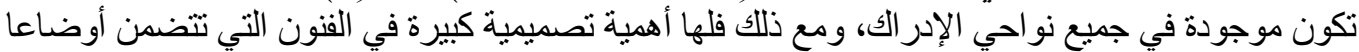

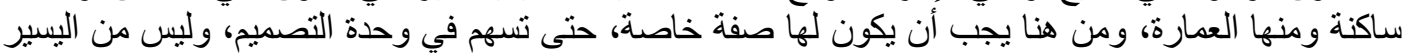

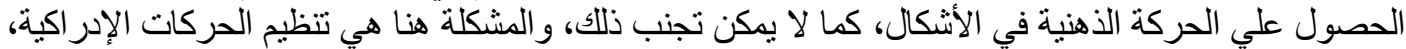

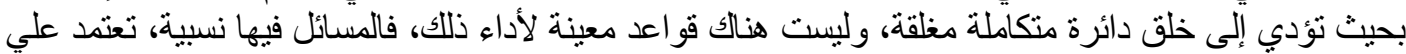
طبيعة التكوين، فلكل شكل، قيم تختلف في حركته الذهنية، أوحتى في أجز اء منه في نفس المجال. [23] فهي حركة بالإيحاء عن طريق ترتيبات عناصر المنشأ وخطوطه و أثناله الأساسية ومستوياته لتعطي الإحساس بالحركة،حيث تكلمت نظريات العمارة عن المفاهيم المختلفة للتكوينات الحركية كالشبكية والثية والخطية

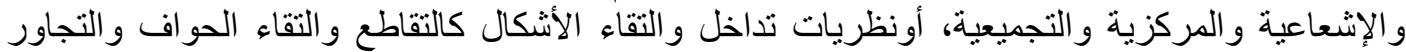

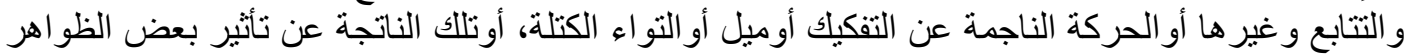

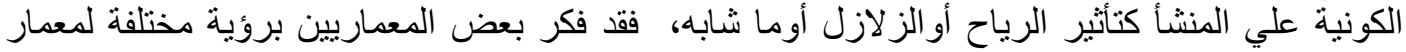

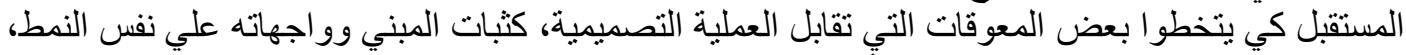

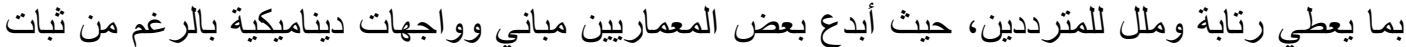

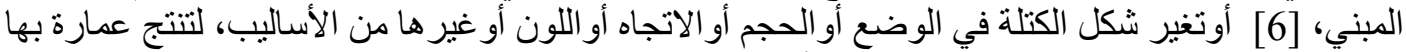

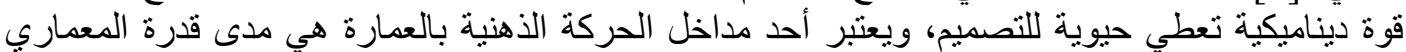

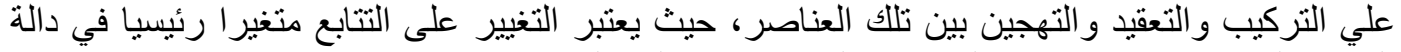
الحركة الديناميكية و الإستاتيكية الذي يقود إلى إحساس عالي بالين الحركة. [22] 
أحسد محسمود صسابر محسـد، خصائص وسعات العمارة الدبناميكية ـ البعد الرابع في العمارة ـ الزمن

بالنهاية نجد أن الحركة تعتمد علي الإحساس المر هف، وقدرة المصمم والإلمام بقو اعد وأسس تصميم الحركة

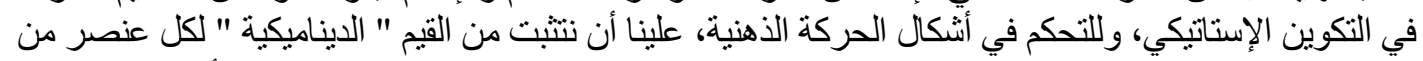

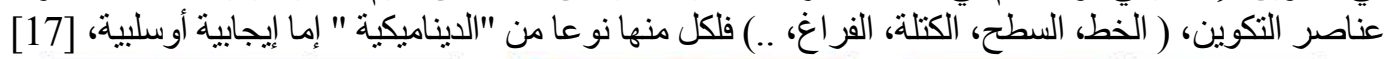
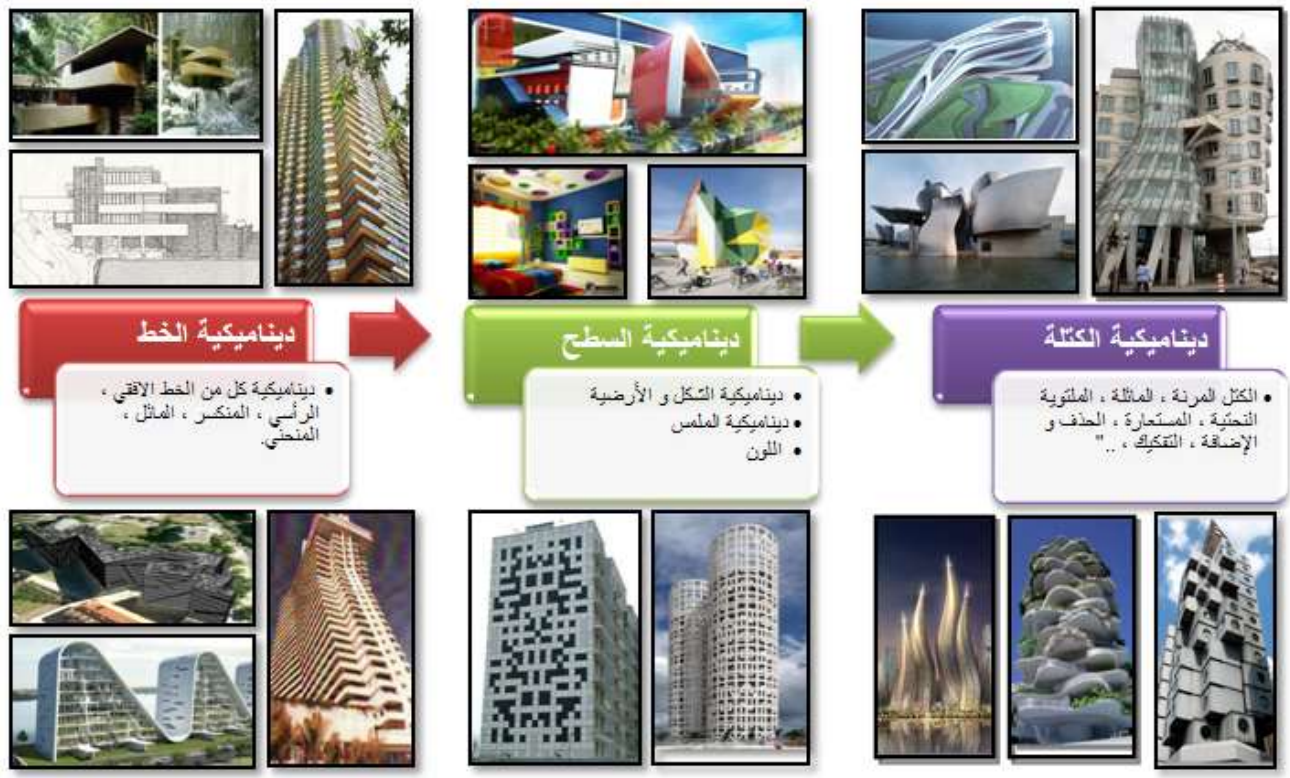

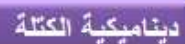

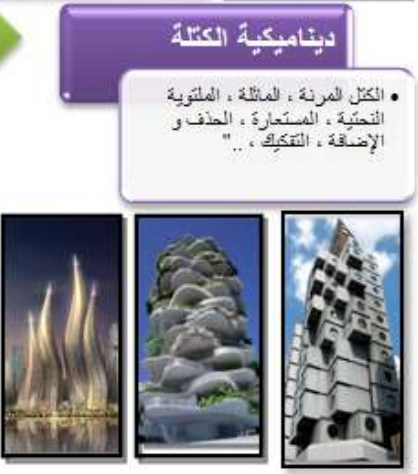

شكل ( 3 ): تطور مفهوم الحركة الذهنية في عملية الإدر الك "ديناميكية العمـارة باستخدام المكونـات الماديـة في

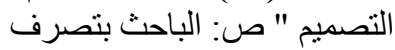

2.4.3. الحركة الموضو عية في المجال المرئسي ( الحركة الدبيامبكبية ):

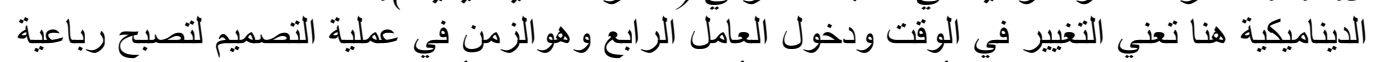

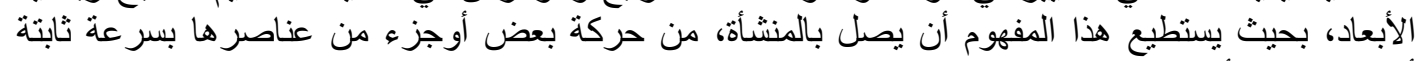

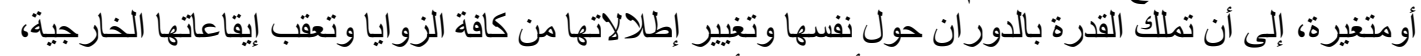
وتتميز الحركة الموضو عية بالمجال المرئي أنها تمثل أكبر مساحة للحركة في عملية الإدر الك. [23

\section{4. مفهوم العسمارة الديناميكية:}

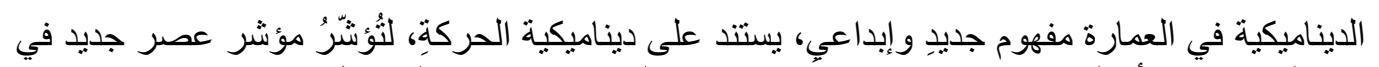

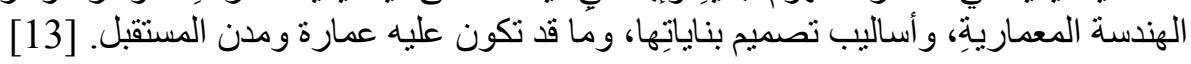

الايناميكية بمفهومها الجمالي: تمثل رؤية جليد للإنسان من حيث دوران المباني حول نفسها لتوفير الإطلالات المنميزة ونهات

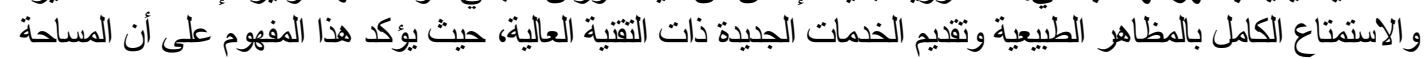

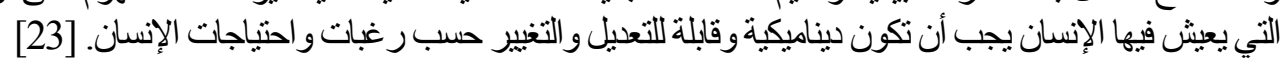

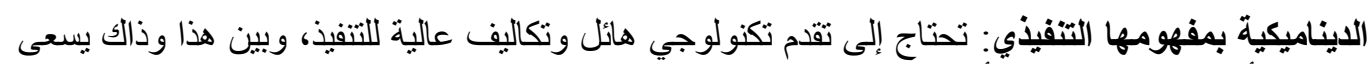

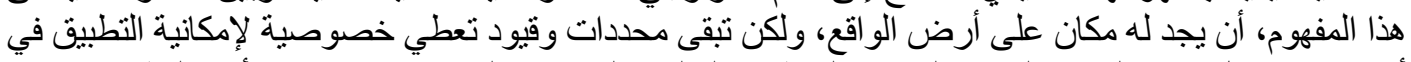

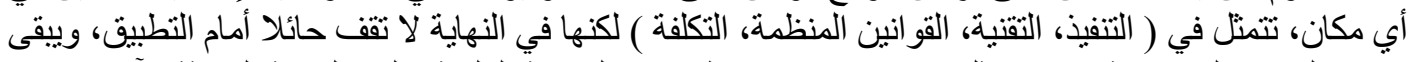

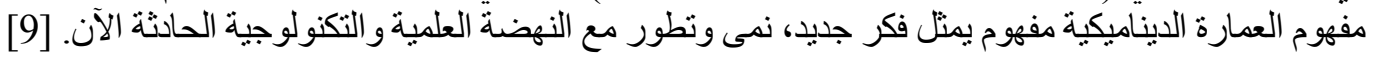

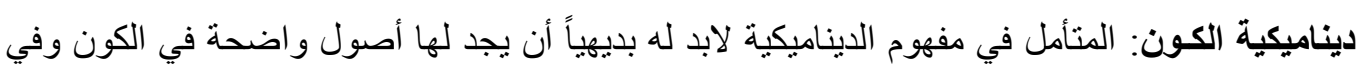

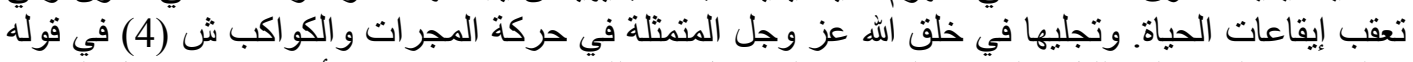

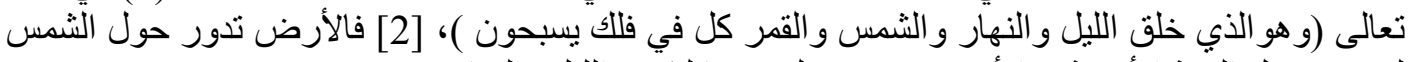

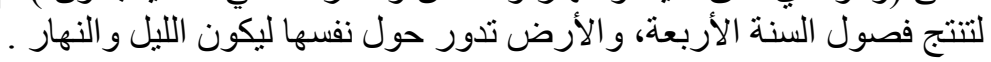


وفي سعي الإنسان للبحث عن الحركة و الانتقال للوصول إلى حياة ومو اقع أفضل، منذ تنقله بالبادية في

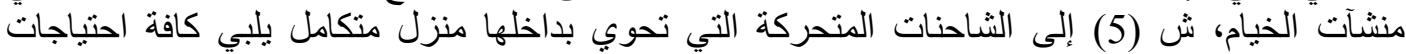

الإنسان، ش (6) وتحقق له اكبر مظاهر الاتنفاع من إيقاعات الحياة من المناظر الطبيعية المختلفة. [13]

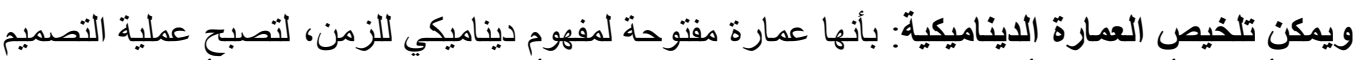

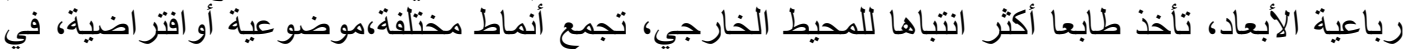

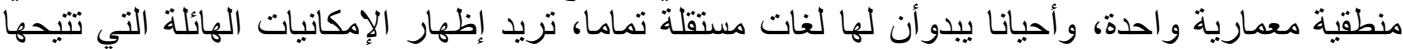

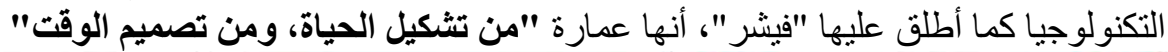
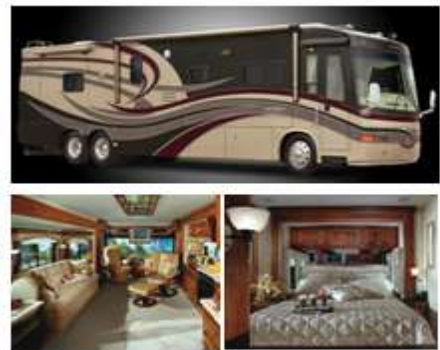

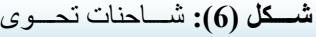

$$
\begin{aligned}
& \text { منــازل بهــا كافـة منطلبـات المعيشـة فئة }
\end{aligned}
$$
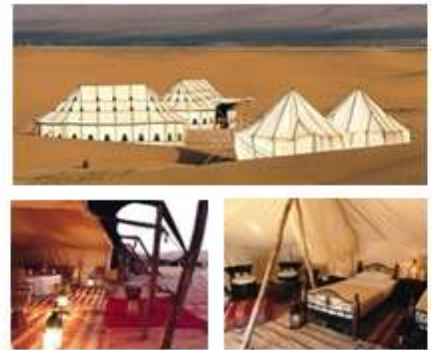

شـكل (5): حبـاة الباديـة داخـل

الخيام - حركة الترحال قديما.

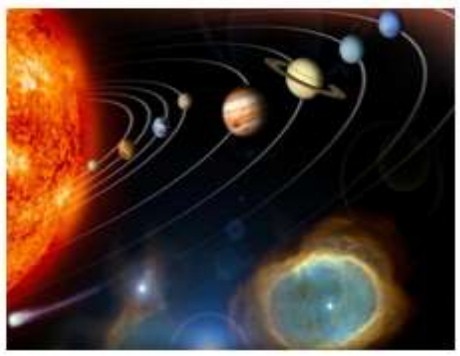

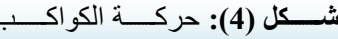
و المجر ات -حركة طبيعية كونية دائمسة.

4. 1. 1. تطور مفهوم العسارة الديناميكية:

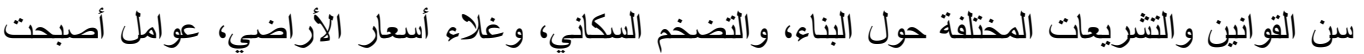

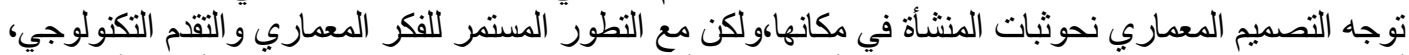

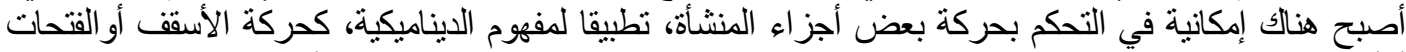

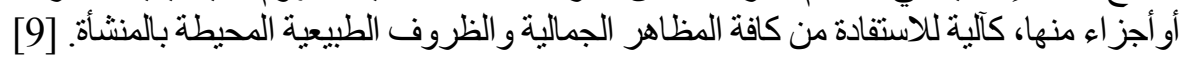

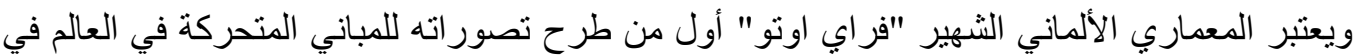

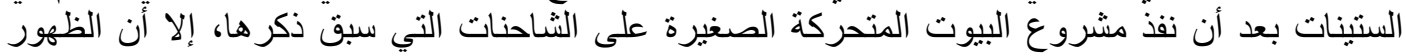

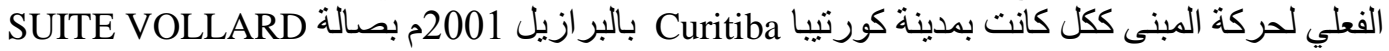

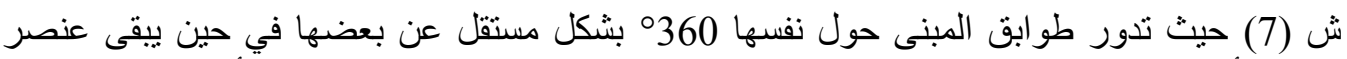

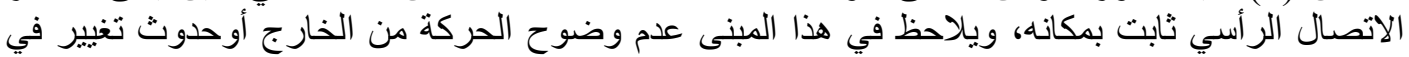

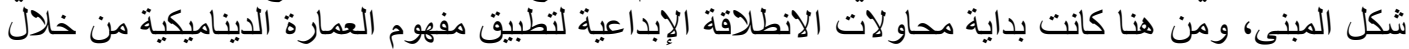
حركة المبنى بكامله وبدأ التسابق الو اضح في هذا المضمار. [27]
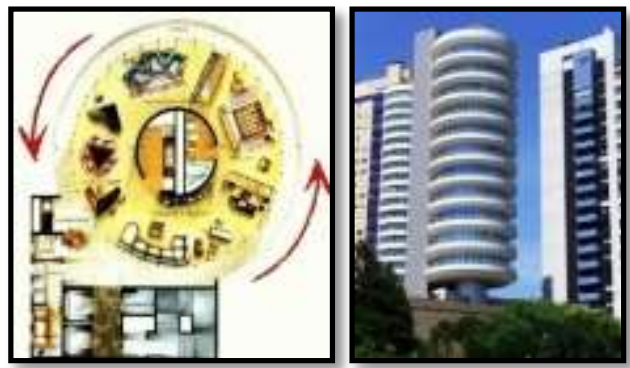

شكل (7):الواجهات و المسقط الأفقي للمبنى المتحرك SUITE VOLLARD ص [34] 
أحسد محسمود صسابر محسـد، خصائص وسعات العمارة الدبناميكية ـ البعد الرابع في العمارة ـ الزمن هن

2.4

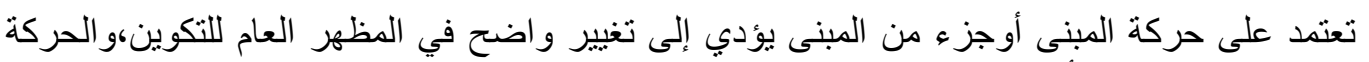
الديناميكية تتقسم إلى عدة أنواع تبعا لمعنى المستو يات الحن المركة:

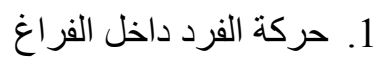

2. 2. حركة بعض مكوكة الفرد دات المبني.

3. ـركة جزئية، للمبنى.

4. حركة تتفاعل مع البيئة الخارجية

5. كركة افتر اضية تتفاعل مع البئة البيئة المحيطة.

6. مركة المبني كليا.

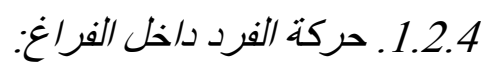

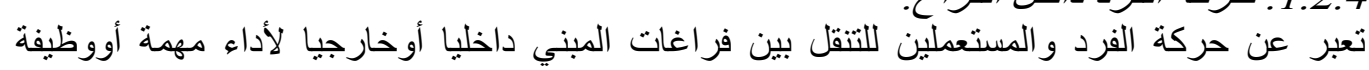
معينة،و هي حركة ضعيفة تعلوو تنخفض تبر تبعا للتصميم

2.2.4 حركة بعض مكونات المبني:

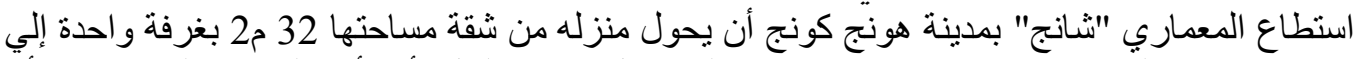

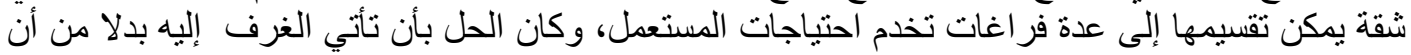

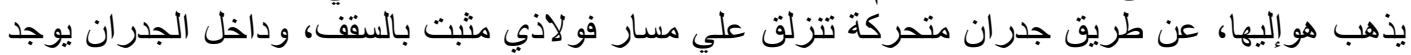

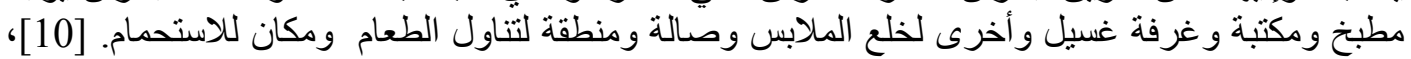
ش ( 8، 9) ومن التقنيات التي طور ها فيشر : نظام الحمام الذكي، يتم تجميعه مسبقا بالكامل للفنادق و المنازل

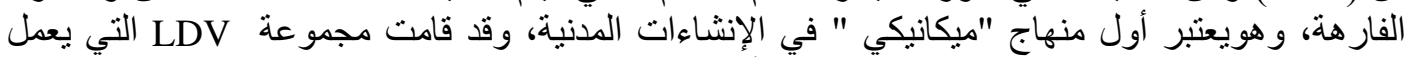
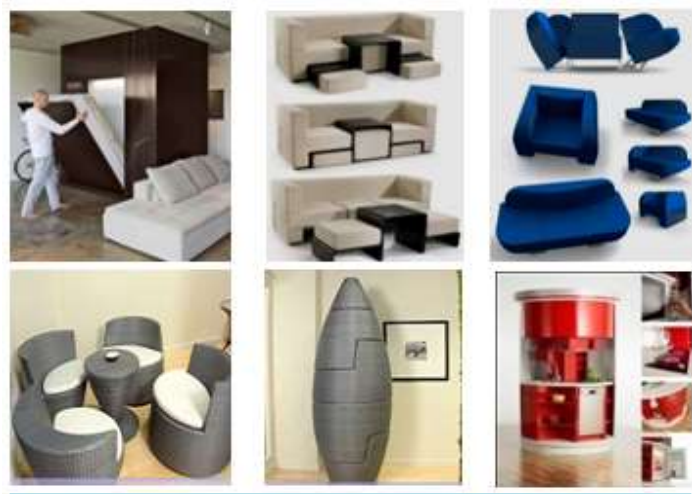

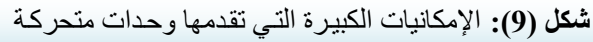
من الفرش تزيد من مساحة الفر اغ الداخلي. [26 الداني

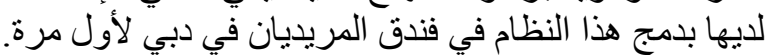

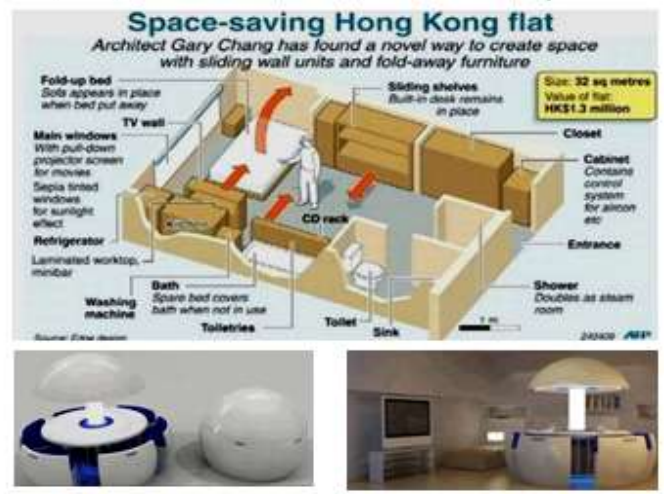

شكل (8): تعظيم الاستفادة من المساحة بتحريك الفرش

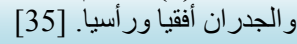

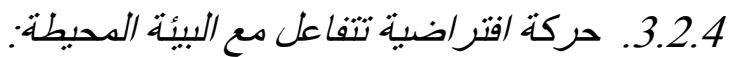

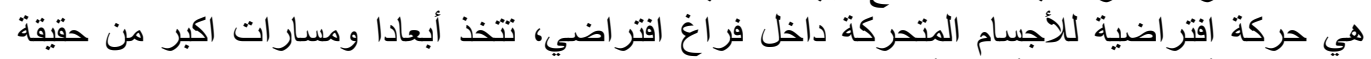

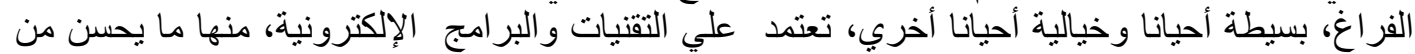

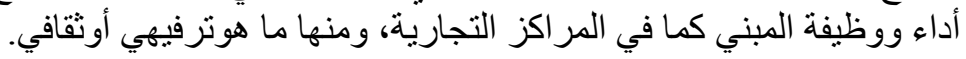

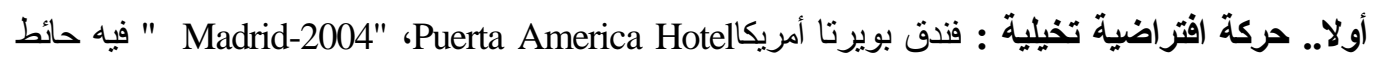

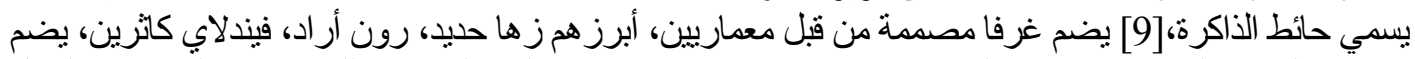

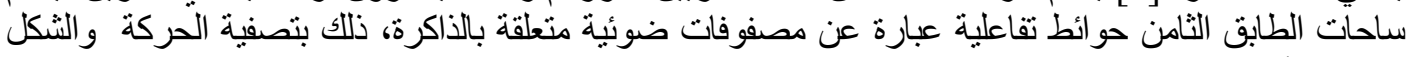
المتحرك أمامها في المكان ويعرض علي سطح الجدران حلقة من الذكريات بفضل واجهة مصفوفة LED كستار من 
الجبس الزجاجي المقوى glass-reinforced gypsum حيث يحتوي علي كاميرات مخفية، وطبقات و ألياف بصرية fiber-optics

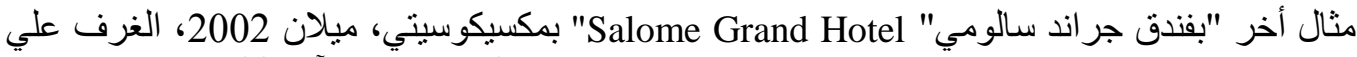

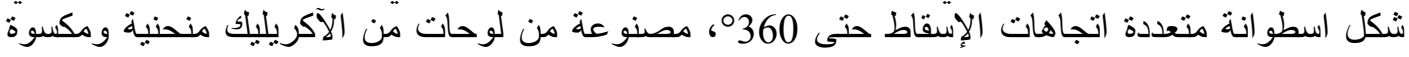
Lumisty TM film الفيديو أولتحقيق مزيد من الترفيه و التفاعلية مع البيئة المحيطة. [19]

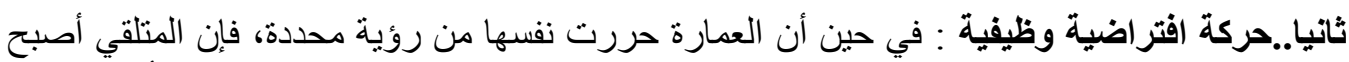

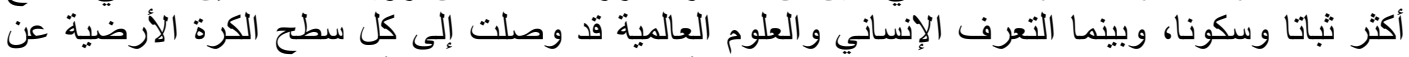

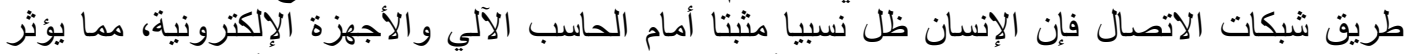

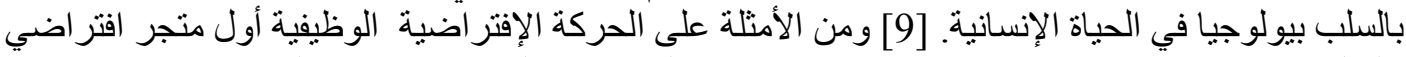

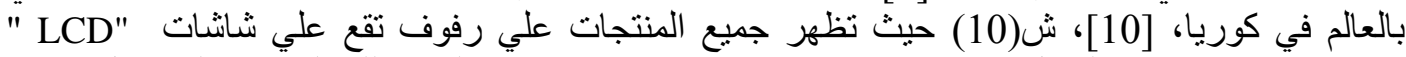

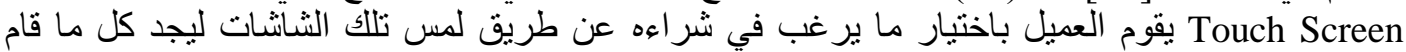

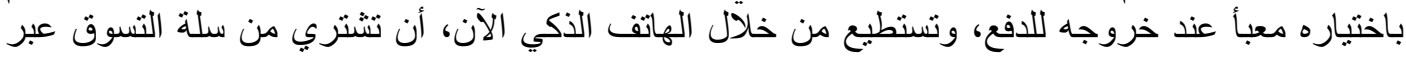

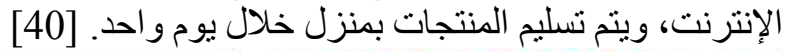

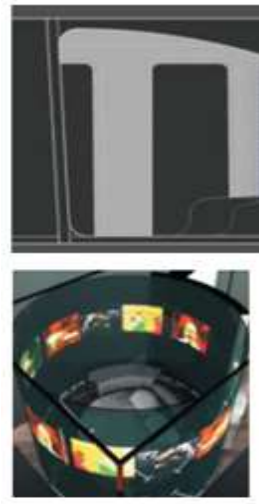

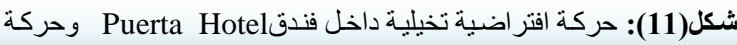

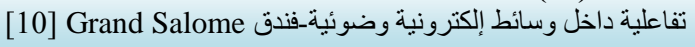
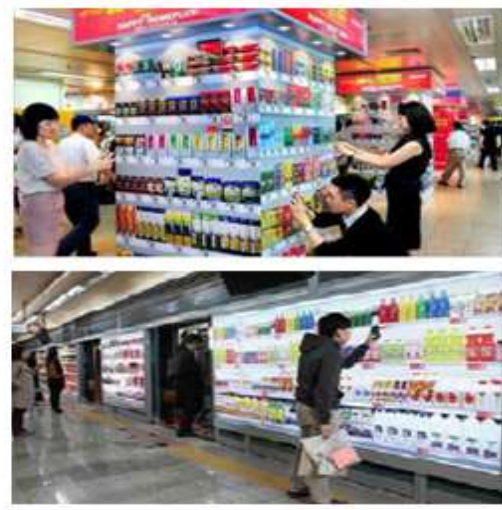

شكل(10): حركة افتر اضية وظيفية علي بروبية

شانشات الكترونية بمر اكز تجارية بكوريا [40]

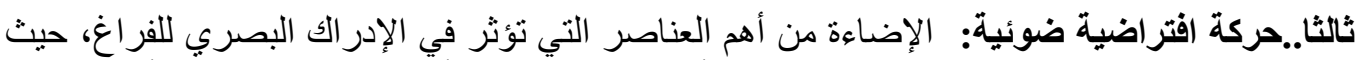

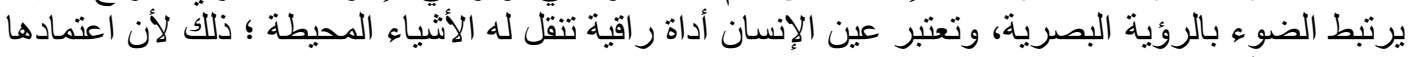

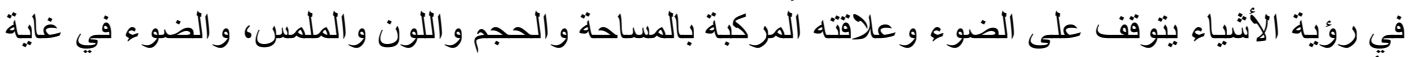

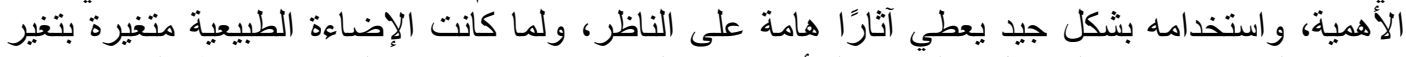

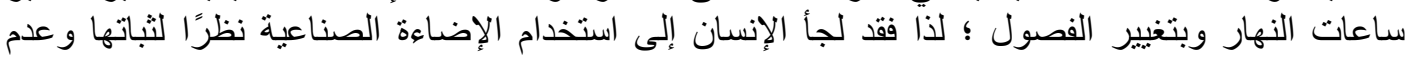

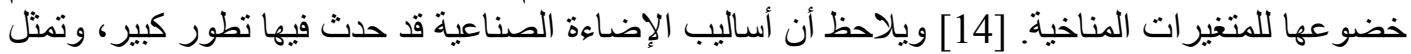

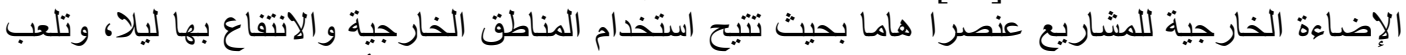

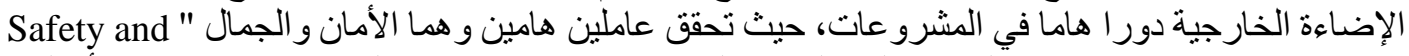
Aesthetic Purposes

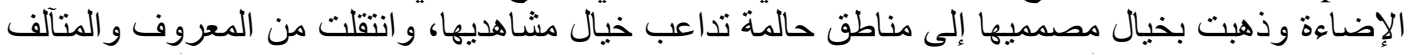

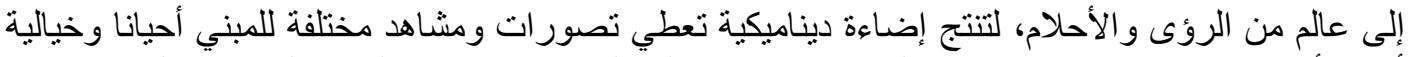

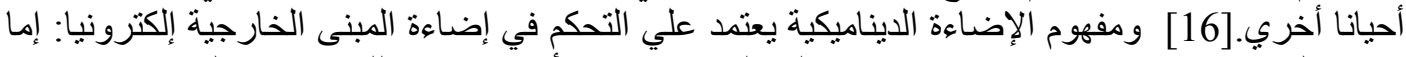

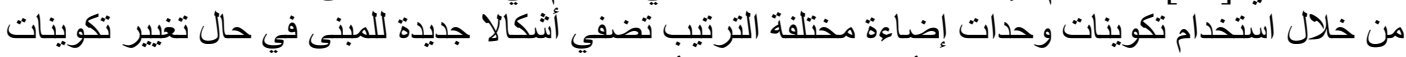

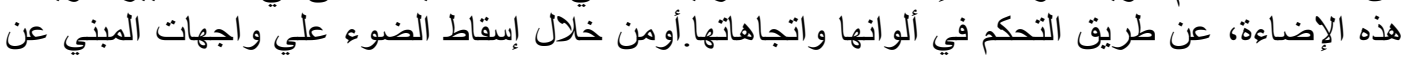
طريق وحدات إسقاط منطورة تعتمد علي تقنيات عالية وبرمجيات اليات رقمية متخصصة في تصميم وتوزيع شكل 
أحسد محسمود صسابر محسـد، خصائص وسمات العمارة الديناميكية ـ البعد الرابع في العمارة ـ الزمن

الإضاءة وطريقة إسقاطها على المبني، بحيث تعطي للمشاهد إحساس كبير بديناميكية وتغير وجهات المبني،

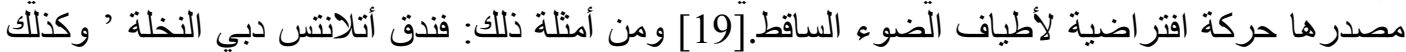
ملعب اليانز أرينا Allianz Arena، حيث نوضح شاكئ (12: 14) كيفية تشكيل وتغير نمط الواجهة الثابتة

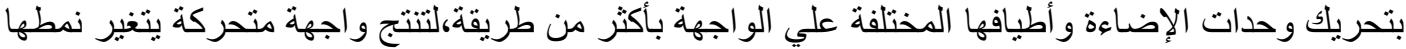

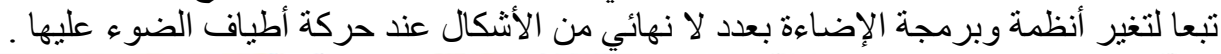

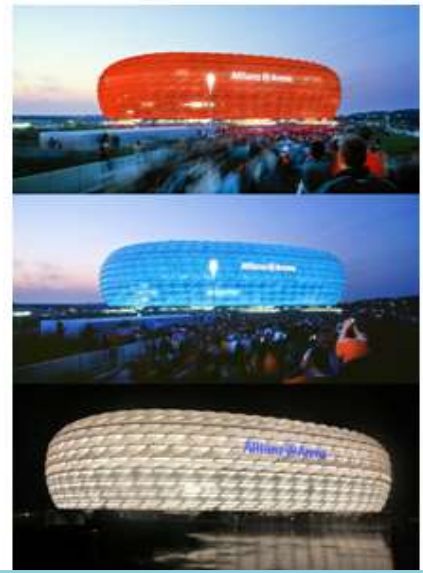

شكل (14): تغير نظـام الإضـاءة

بملعب Allianz Arena - نئيرل

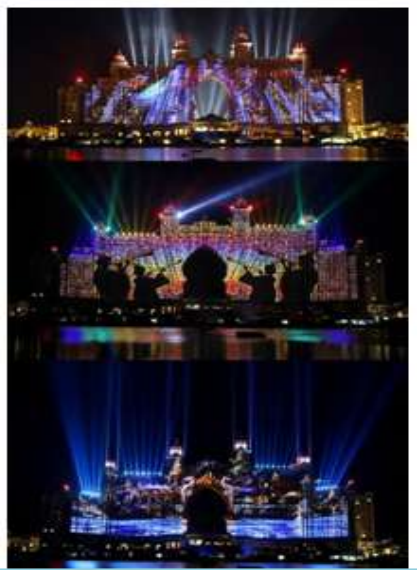

شـكل (13): التلاعـب بالإضـاءة

نمط الو اجهة بفندق أتلانتس دبي. [13)

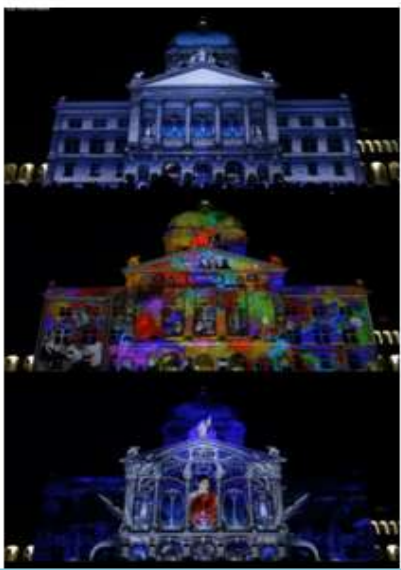

شكل (12): حركة الضوء يغير

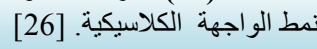

4.2.4. حركة أجزاء دن المبنى.

أولا..حركة وجهات المبني: Dynamic façade في أوقات سابقة، كان الطابع العام للوجهات يتحدد

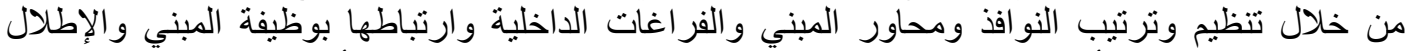

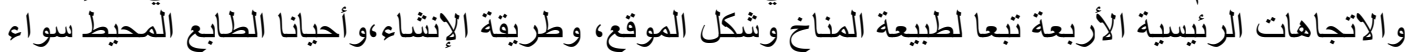

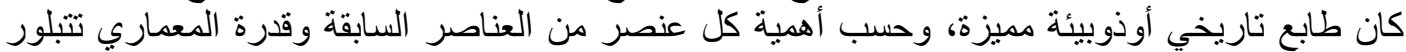

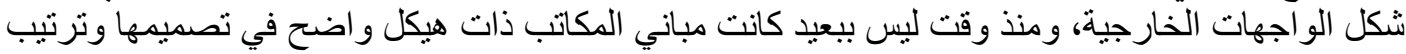

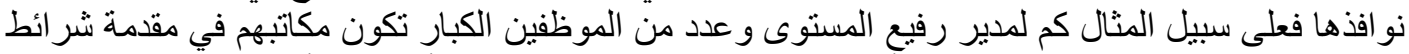

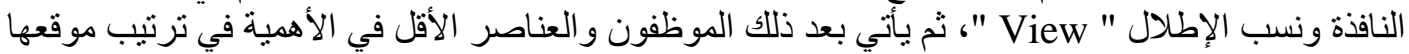

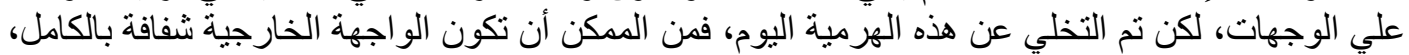

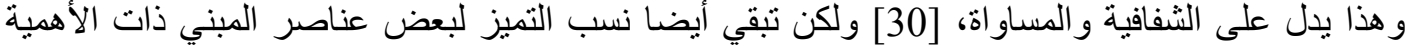

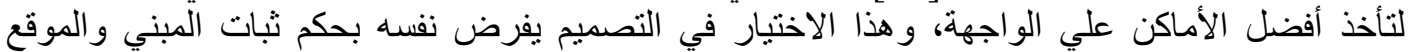

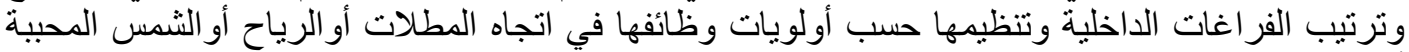

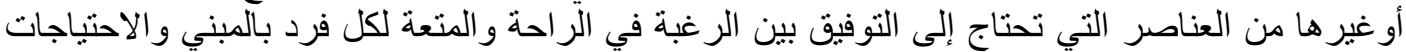

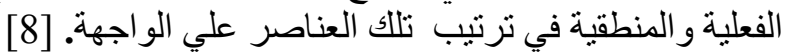

هناك أسباب أخرى تتعلق بثبات المبنى وواجهاته على نفس النمط مدى الحياة بما يعطي رتابة وملل

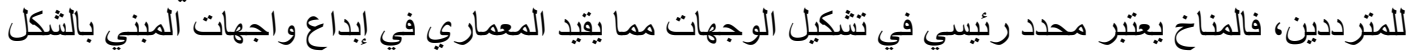

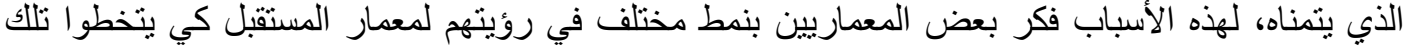

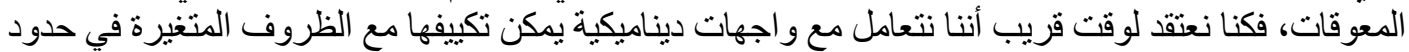

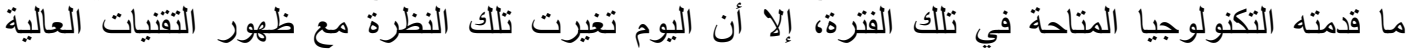

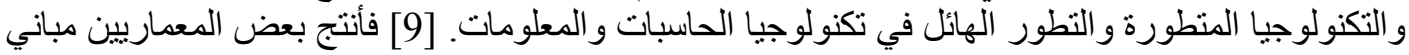

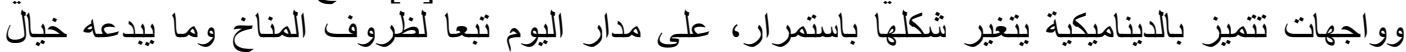

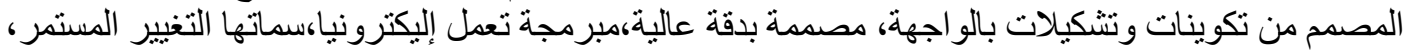
هدفها المتعة لكل فرد بالمبني، و أكبر مثال على ذللك مبنى "Kiefer showroom" النمسا "Austria-2008 " 
للمعماري Austria، Graz،" Giselbrecht Partner Architecture ، حيث تم عمل واجهة المعرض بحيث

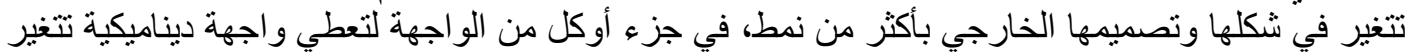

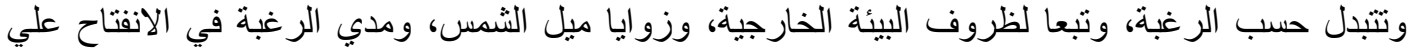

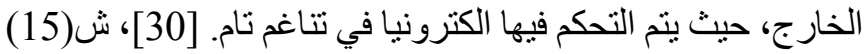

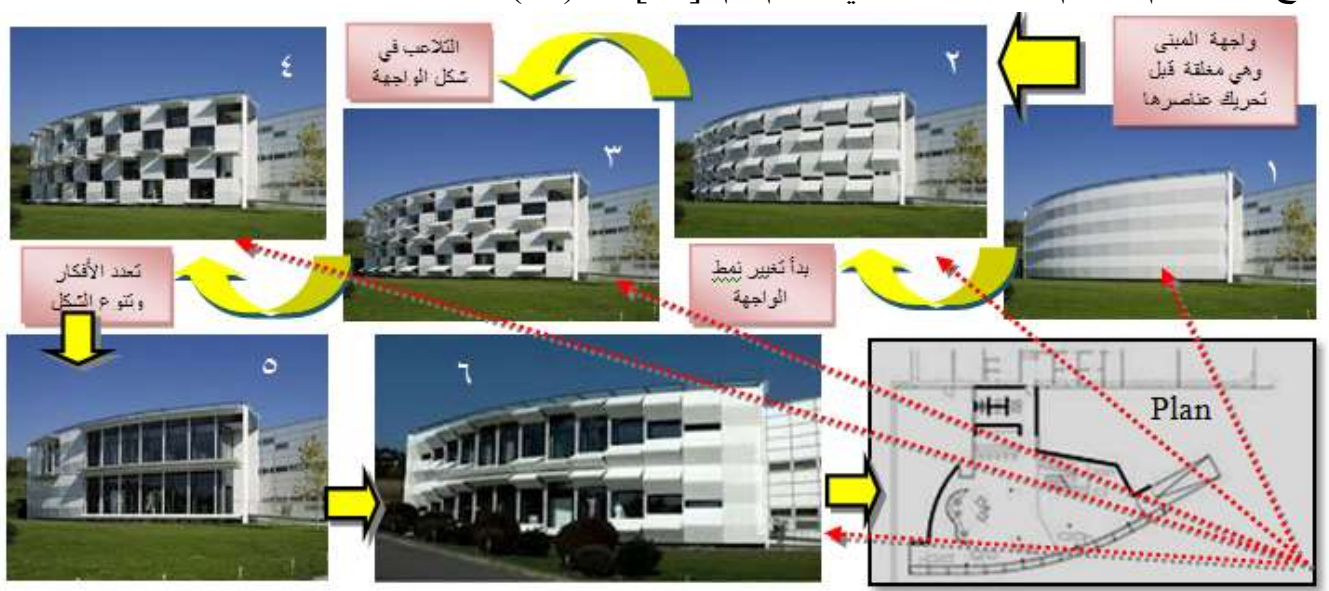

شكل (15): الو اجهات الديناميكية المتحركة لقاعة Kiefer technic showroom" ويظهر التنوع الكبير في

الثكل عند تحريك عناصر الواجهة - ص: الباحث بتصرف التهن بالاستعانة ب [30]

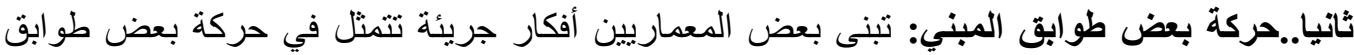

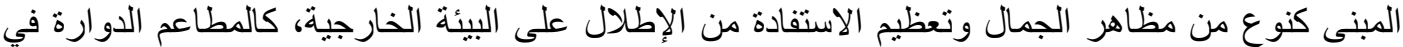

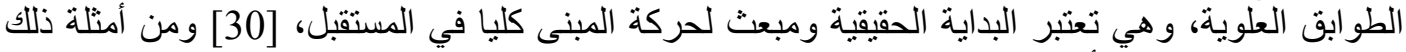

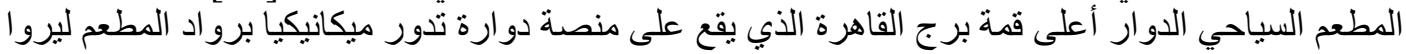

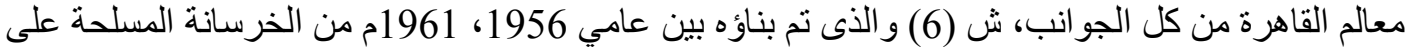

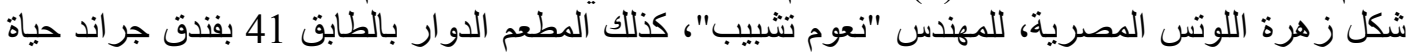

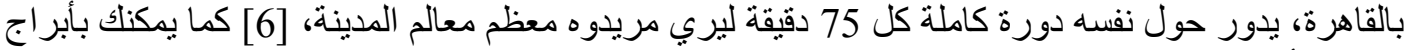

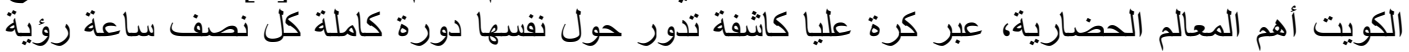

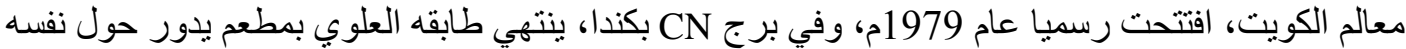

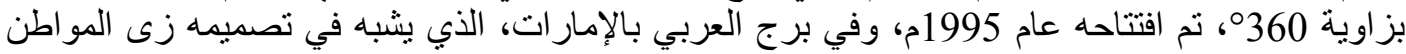

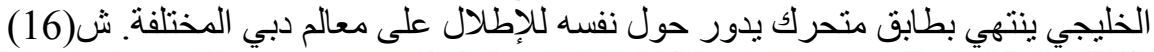
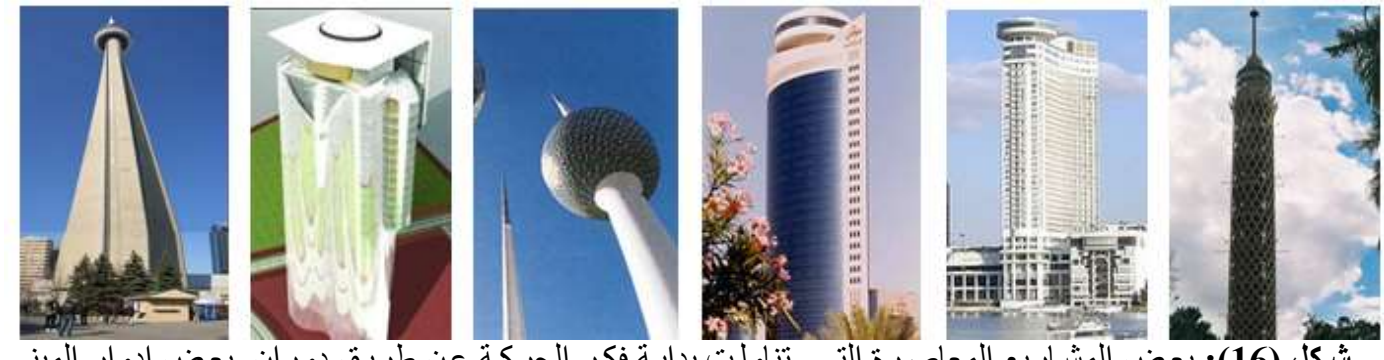

شكل (16): بعض المشـاريع المعاصرة التي تنتاولت بدايـة فكر الحركة عن طريق دوران بعض ادوار الإر المبني

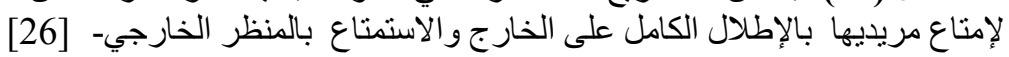

ثالثا..حركة أسقف وأرضيات المبني: أناحت حركة الأسقف بالإضافة لتغيير المظهر الخارجي و الداخلي

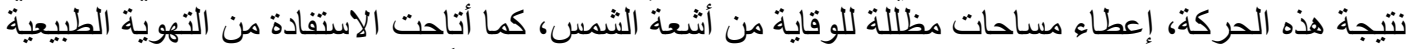

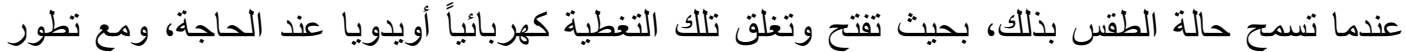
تكنولوجيا البناء ظهرت أنواع و أشكال مختلفة من التغطية المتحركة تفتح وتغلق إلبكترونيا عبر 
أحسد محسمود صسابر محسـد، خصائص وسمات العمارة الديناميكية ـ البعد الرابع في العمارة ـ الزمن

حساسات تبرمج حسب كمية الضوء أو الحرارة المعرضة لها. [23] ومن الأمثلة علي حركة التغطية ما تم في

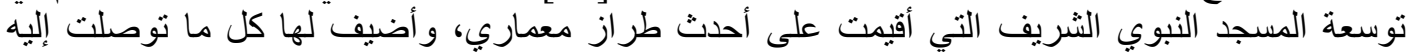

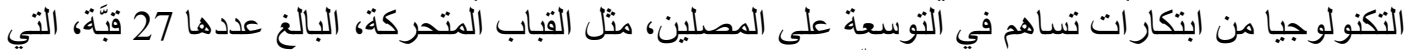

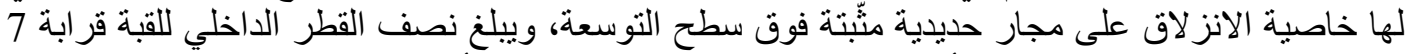

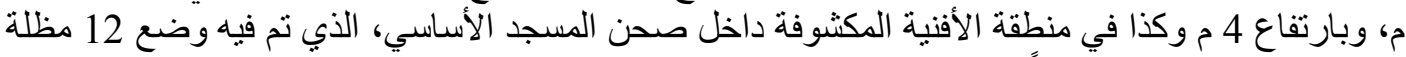

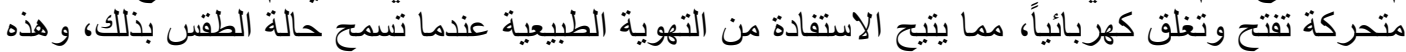

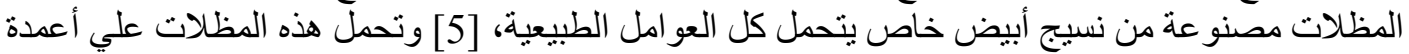

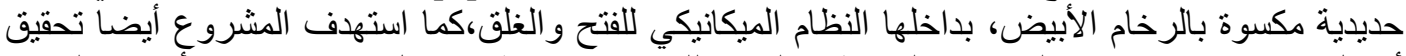

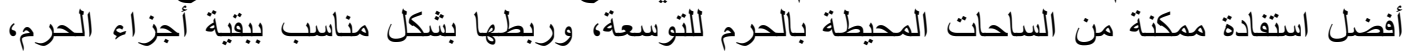

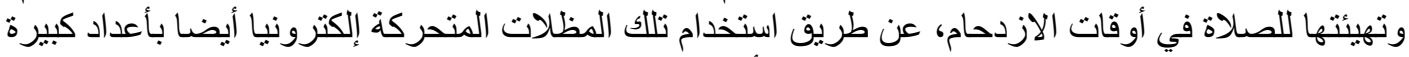

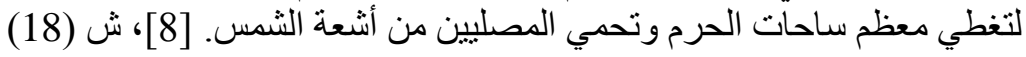

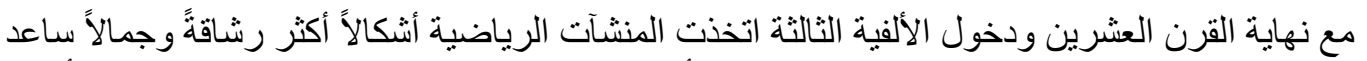

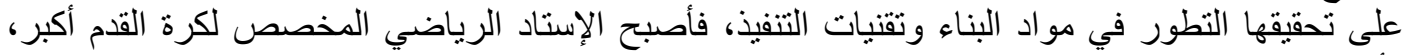

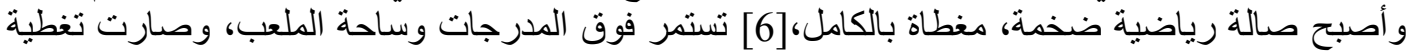

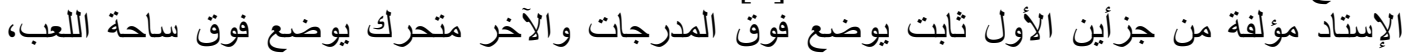

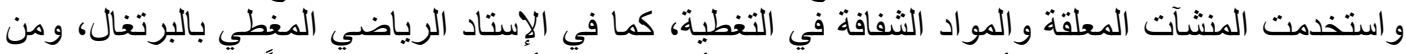

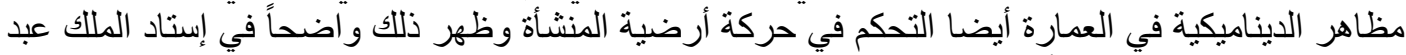

الله الدولى من خلال حركة أرضية الملعب من داخل الصالة إلى خارجها و العكس. [9]، ش (17)

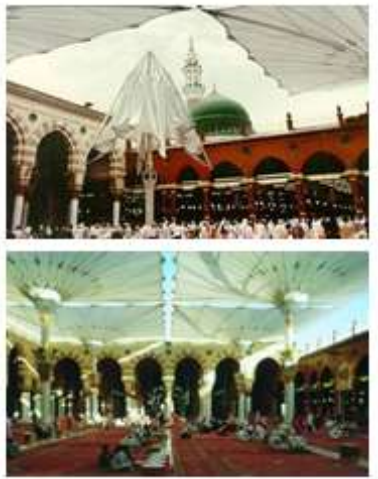

شـكل (18): القبـاب و المظـلات المتحركـة بأفنيـة وسـاحات

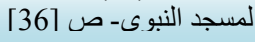
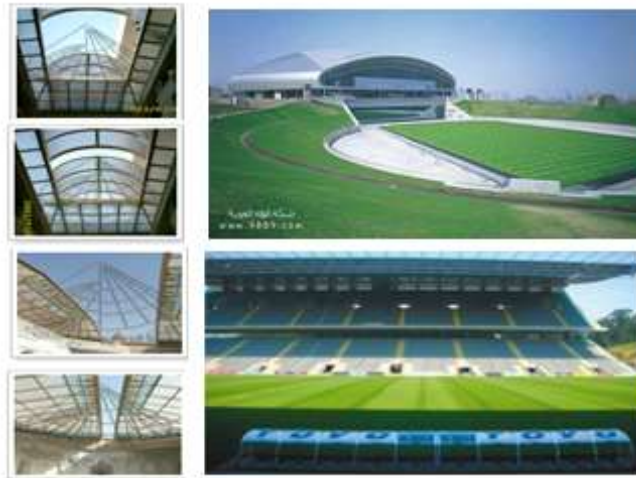

شكل ( 17 ) ): حركـة أرضـيات إبـتاد الملك عبدا لله-

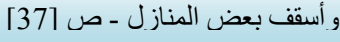

رابعا.. حركة تثفاعل مع البيئة الخارجية (حركة العناصر المائية): العناصر المائية المتحركة والتحكم

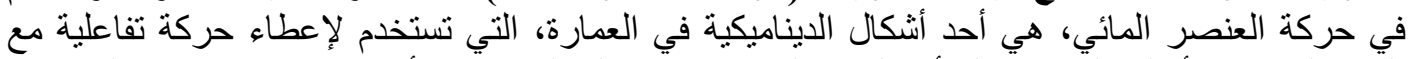

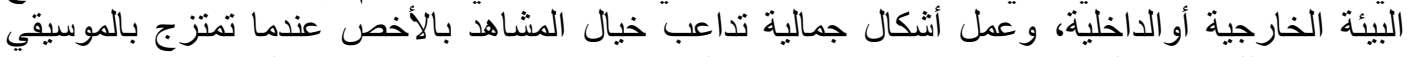

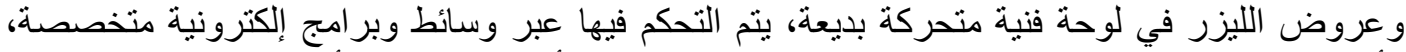

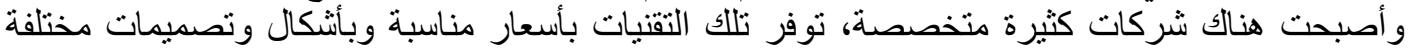
تستطيع أن تراها بتجربة فعلية واتخاذ ما هومناسب للموقع، ومن أهم الأمثلة علي ذللك نافورة دبي الراقية واقصة

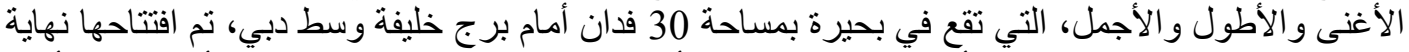

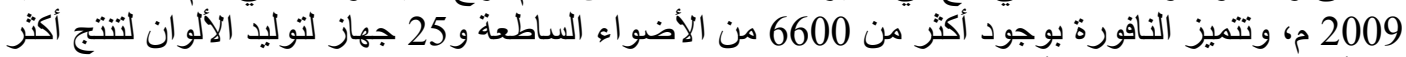

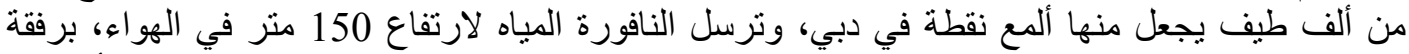

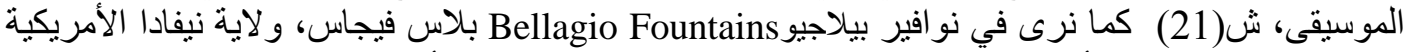

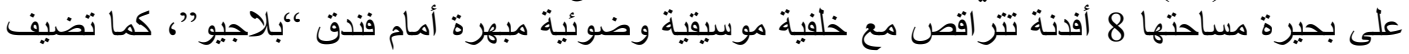


بألو انها وتدفق المياه و عزف الموسيقى مشهداً رومانسياً وسط المدينة الغارقة في الأعمال التجارية. ش (20)

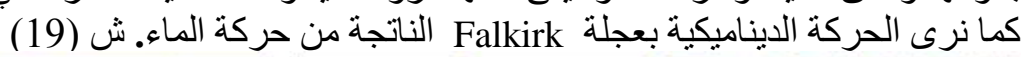
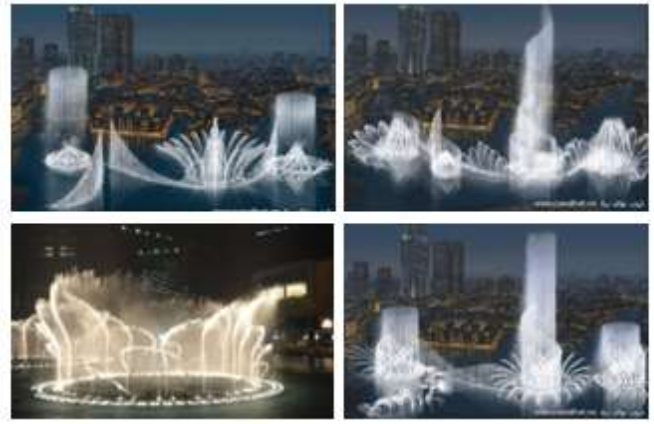

شكل (21): النافورة الر اقصـة بـدبي أمسام بـرج الخليفة

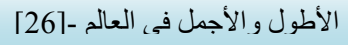

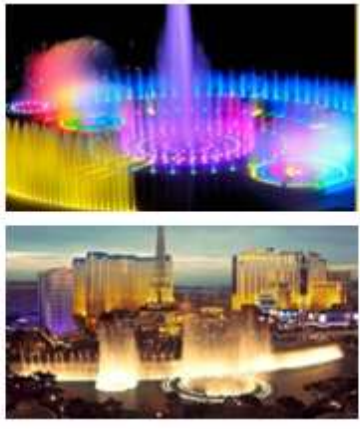

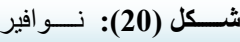

بلاجيو بلاس فيجاس- [26] ن

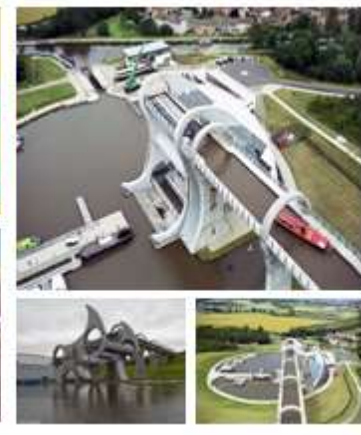

شــــل (19): حركـــــة

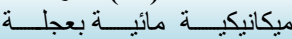

خامسا..حركة المبنى كليـا: حركة المبنى كليا تمثل رؤية جديدة للإنسان من حيث دور الإن المباني حول

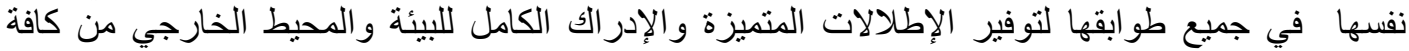

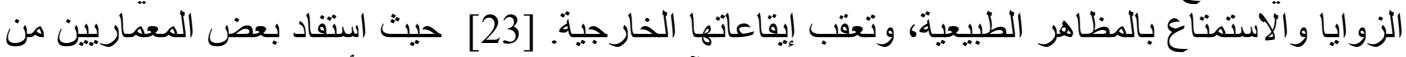

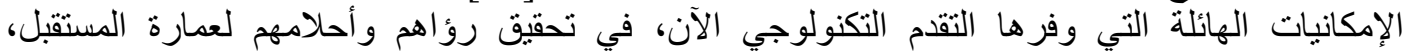

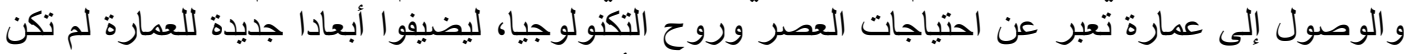

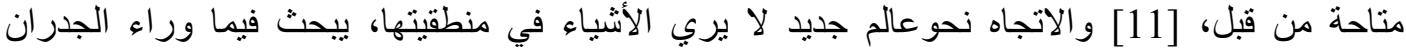

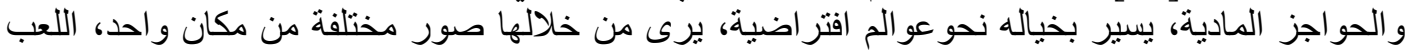

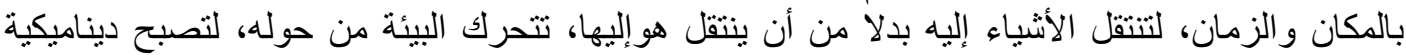

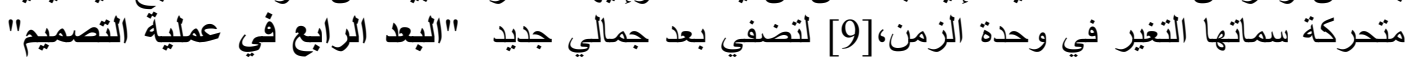
"الزمن" ليتحول المبني من الثبات إلى مبني نشط فعالّ متحول، يتفاعل مع الداخل ودئ والخارج في في آن واحد. أضاف هذا البعد الجديد فوائد نفسية وبيئية وجمالية متعددة، كالمتعة والإثارة، فالحركة تمثل التغيير

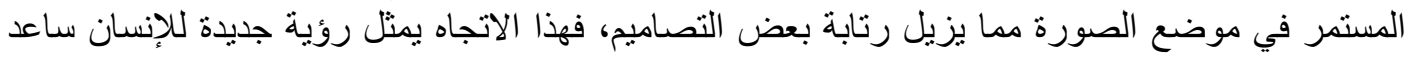

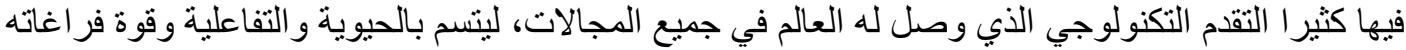

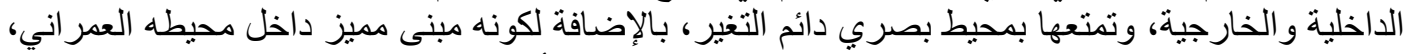

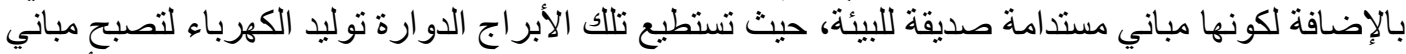

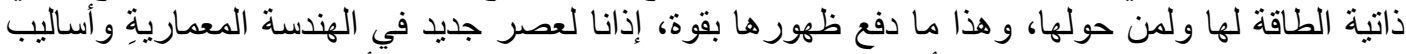

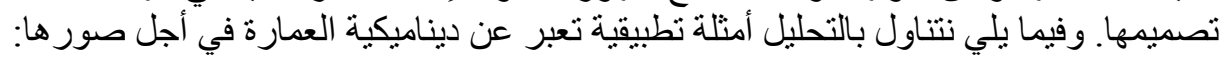

سادسا.. دراسة تحليلية وتطبيقية لبعض نماذج معمارية اعتمدت في فلسفة تصميمها كليا علي فكر

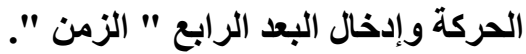

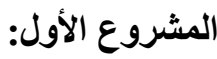

أولا: الوصف العام للمشروع : [29]، [28]

اسم المشروع: البرج الدوار بلبي- "2007:2010"

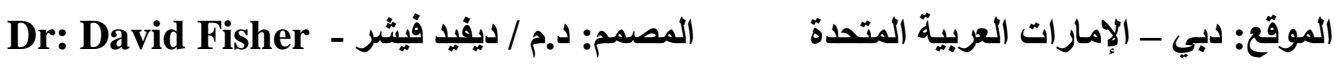

تقدم الثركة الإيطالية .Tower Rotating G. التابعة لمجموعة Dynamic Architecture G. إبداعها

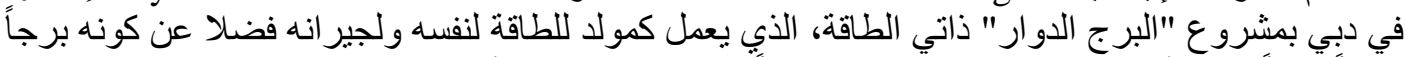

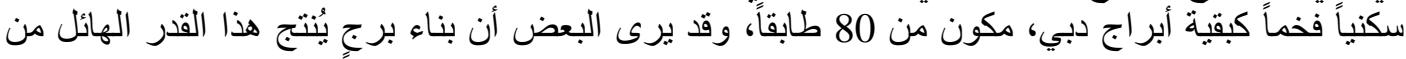


أحسد محسمود صسابر محسـد، خصائص وسعات العمارة الدبناميكية ـ البعد الرابع في العمارة ـ الزمن

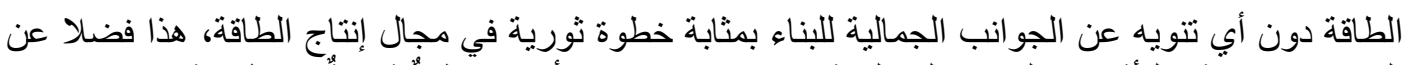

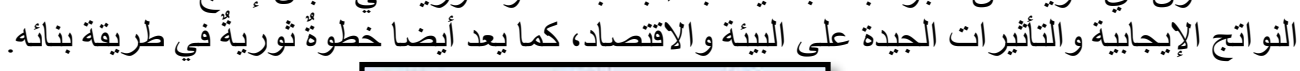

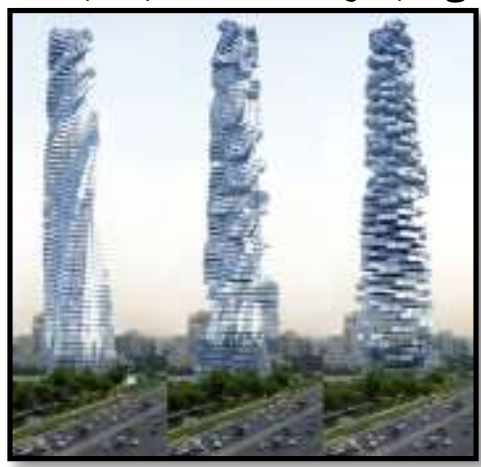

ثانيا: الفكر التصميمي : Design Concept

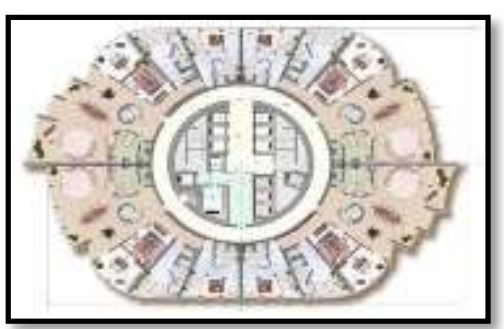

يتيح البرج الديناميكي إمكانيات تصميم غير محدودة، في

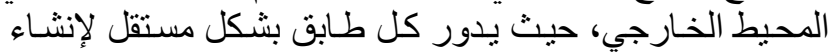

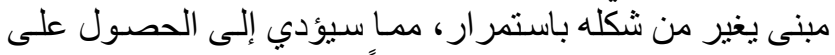

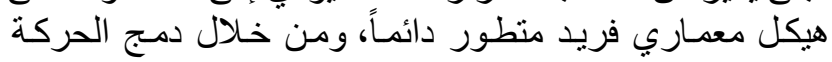

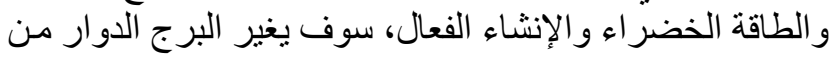

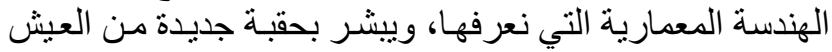

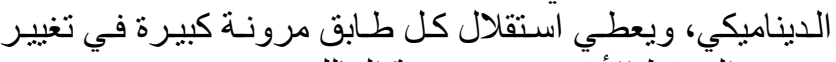
تصميم المسقط الأفقي حسب ريب رغبة المالك.

$$
\text { مكونات البرج الاوار }
$$

• بتكون من عمود معدني Core System تلتف حوله الطو ابق.

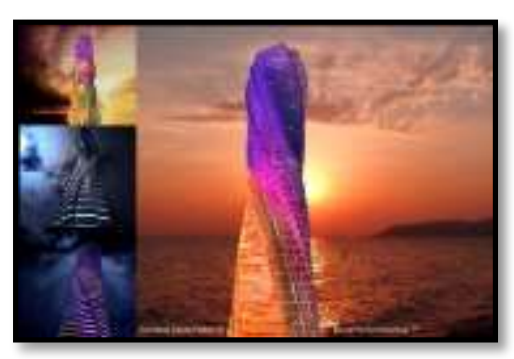

• • • • • بين كل طابقي ترس دوار يلتف فوقه الطابق بشكل مستقل.

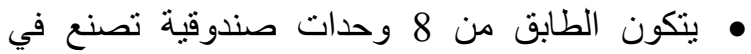

المصنع ثم تركب بالموقع، ويتم تصنيع الدور خلان ثلاث أيام فقط . ثرد

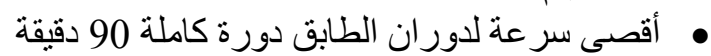

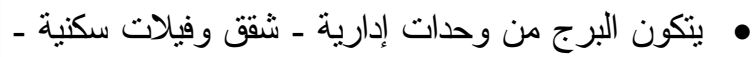
فندق 6 نجوم- مو اقف للسيار ات تصل والى إلى الثقق و الفيلات.

\section{ثالثا : القيم الجمالية المكتسبة من حركة المبني :}
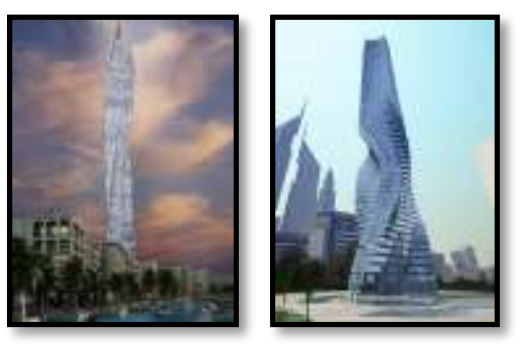

أبرز ميزة للمبنى سوف تكون دور ان معظم الطوابق حول

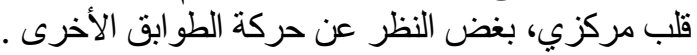

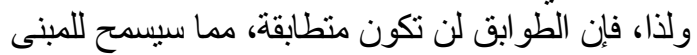
بأن يغير شكله باستمر ار، في في البيئة الخارجية.

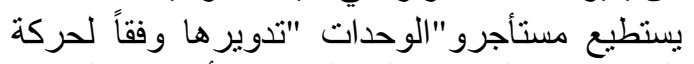
الشمس من الشروق إلى الغروب، أوناحية المطلات

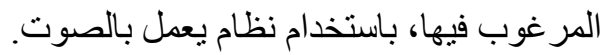


رابعا : العوامل البيئية المكتسبة:

ذكر فيشر أن" البرج الديناميكي مستدام وصديق للبيئة، حيث يتمتع بالقدرة على توليد الكهرباء لنفسه، و المباني

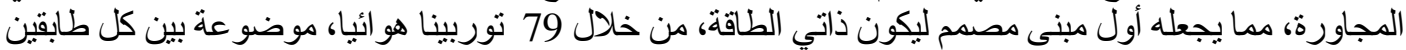
بشكل أفقي، مما يجعله محطة لتوليد كهرباء خضر اء ضخمة، لها القدرة على توليد طاقة تكفي لتزويد 5 أبر اجٍ .

$$
\text { فضلا عن ذلك : }
$$

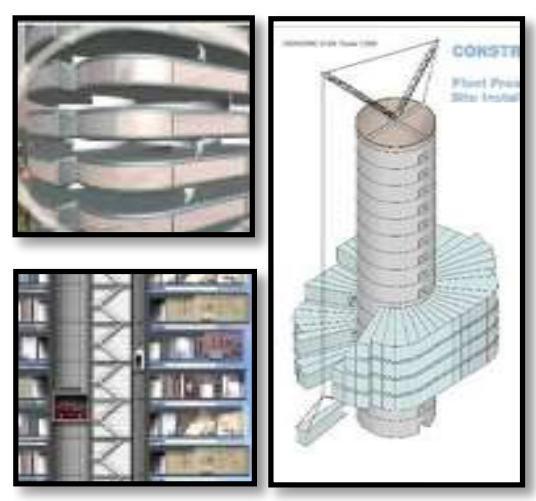

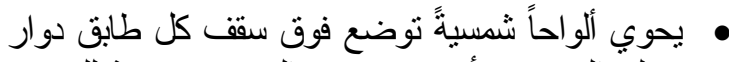

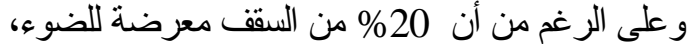
إلا أنه بفضل الرغ دن النظام الدوار، تحصل الخلايا الكهروضونئية

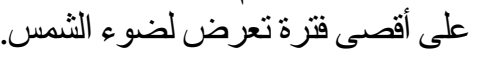

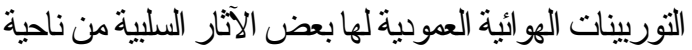

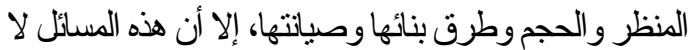

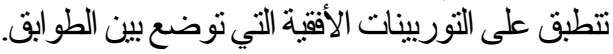

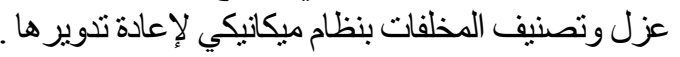

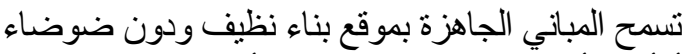

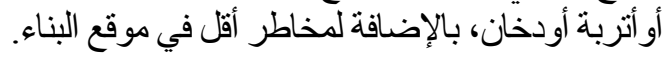

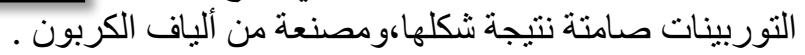

$$
\text { البعد الإنشائي والتقتي : }
$$

يعتبر البرج الديناميكي أول ناطحة سحاب تبنى بالكامل من أجزاء سابقة التجهيز ، حيث يتم بناء القلب بالموقع بـاء

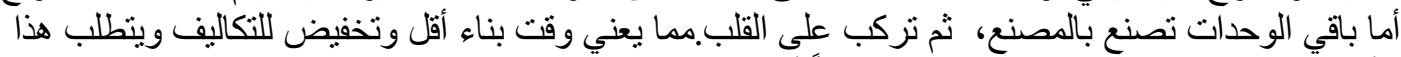

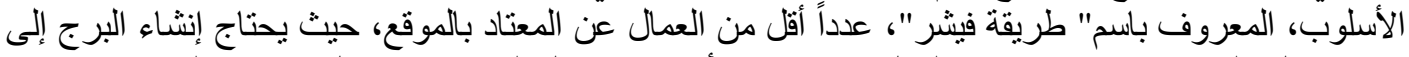

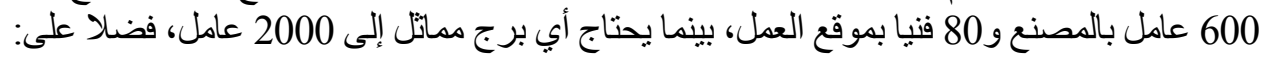

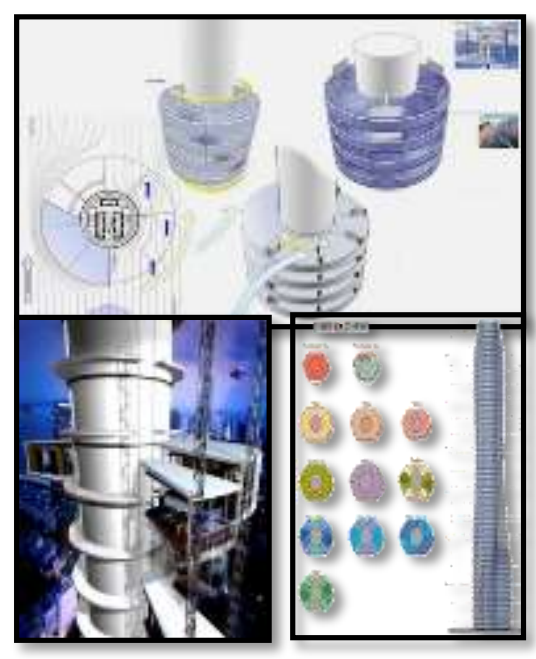

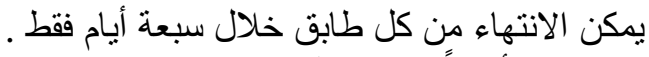

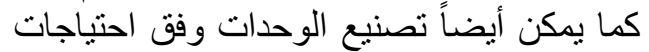

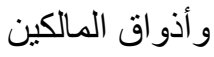

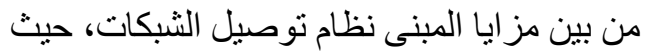

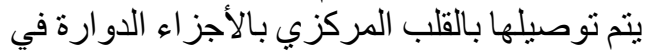

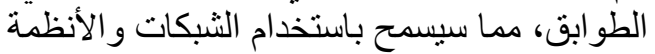
داخل الثقق بأسلوب معتاد

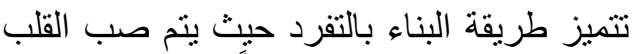

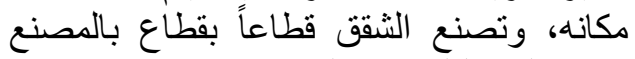
وتوصيلها بالقلب عند التجميع.

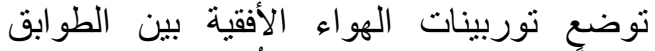
مرئيةً، لا تحتاج إلى دعائم لنتُبتها، و وعلى مقربةٍ

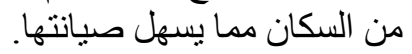

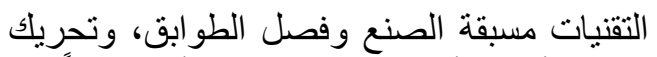
الرياح أغلب أجزاء البناء تجعله أكثر ثباتاً في البهاء وجه عو امل الطبيعة عن أي بناءِ آخر.

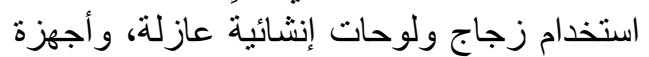

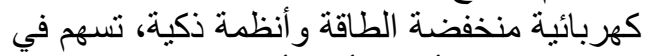
فعالية الطاقة. وأنظمة أمان أكثر تقدما. 
أحسد محسمود صسابر محسـد، خصائص وسعات العمارة الدبناميكية ـ البعد الرابع في العمارة ـ الزمن

خامسا: البعد الاقتصادي:

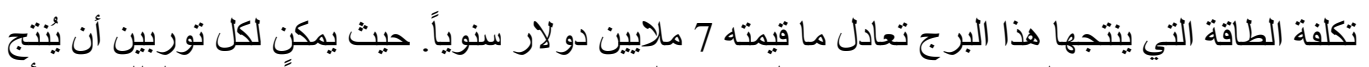

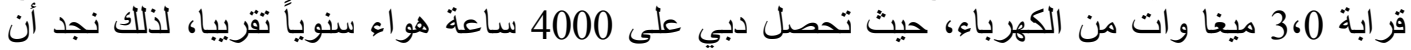

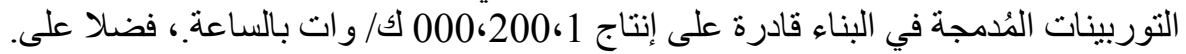

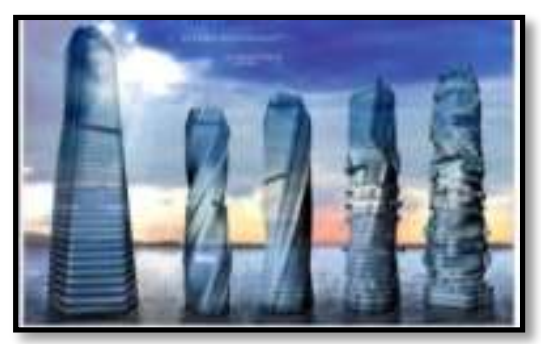

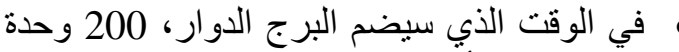
سكنية؛ فإن أربع توربينات فقط سنكفي لتزويد المبنى بحاجته من الطاقة

الفائض من الطاقة بمكنها إضاءة الطنهة المباني

المجاورة، فضلا عن الطاقة الثمسية الأخرى المئي المنتجة من المبنى.

• وقت التنفيذ أقل نتيجة الوحدات سابقة الصنع مما يقلل التكلفة.

عدد عمال وفنبين اقل من البناء التقليدي مما يقلل من التكاليف ونسب وفئ التأمين و المخاطر. المشروع الثاني : المن

أولا: الوصف العام للمشروع: [29]، [28]

اسم المشروع:"Rotating Skyscraper "2007:2010

Dr: David Fisher - المصمم: د.م / ديفيد فيشر

الموقع: موسكو-روسيا

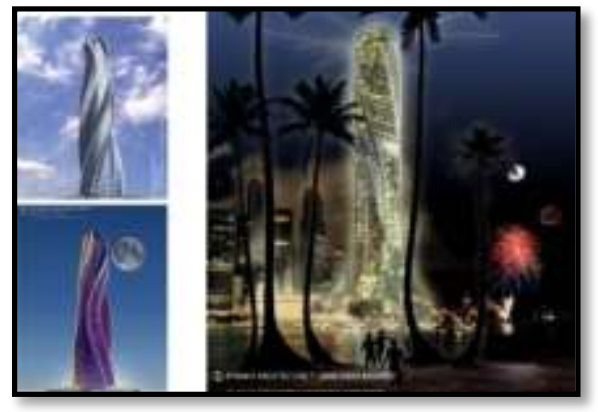

تقدم مجمو عة.Dynamic Architecture G.

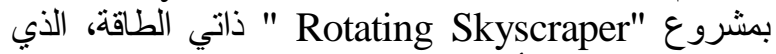

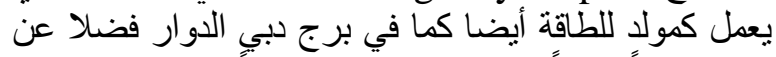

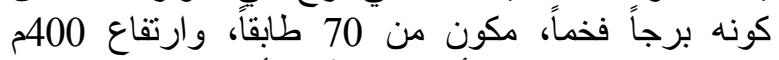

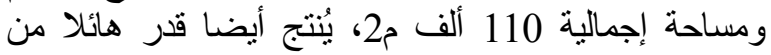
الطاقة فضلا على الجوانب الجمالية للبناء، و النواتج الإئية الإيجابية

و التأثثيرات الجيدة على البيئة و الاقتصاد، وطريقة بنائه.

ثانيا: الفكر التصميمي : Design Concept
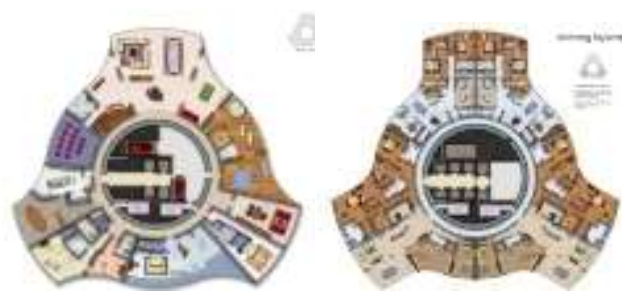

يتيح البرج إمكانيات تصميم غير محدودة، في المحيط

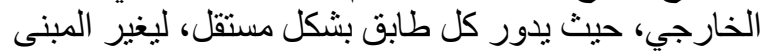

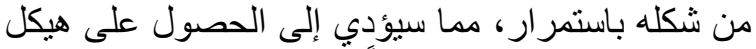

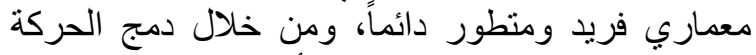

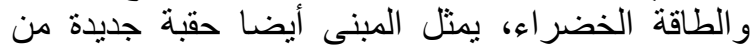

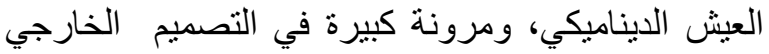

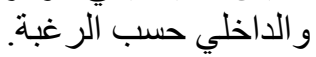

ثالثا : النظام الإنشائي ومكونات البرج الدوان
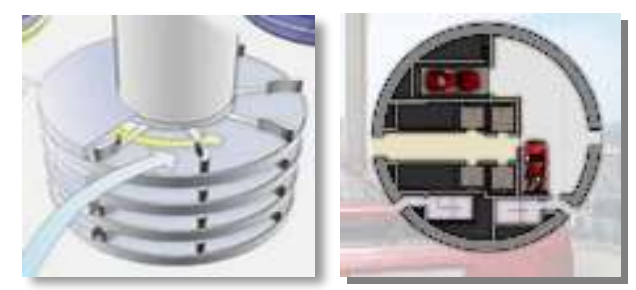
• يتكون من Core System تلتف حوله الطو ابق.

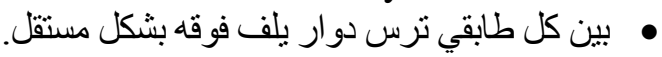
• بتكون الطابق من وحدات صندوقية مسبقة الصنع. • أقصى سر عة لدور ان الطابق دورة كاملة 90 دقيقة 


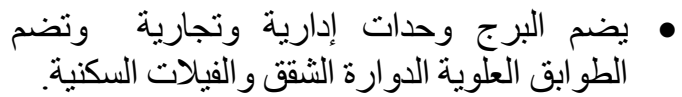

رابعا : القيم الجمالية المكتسبة من حركة المبني :
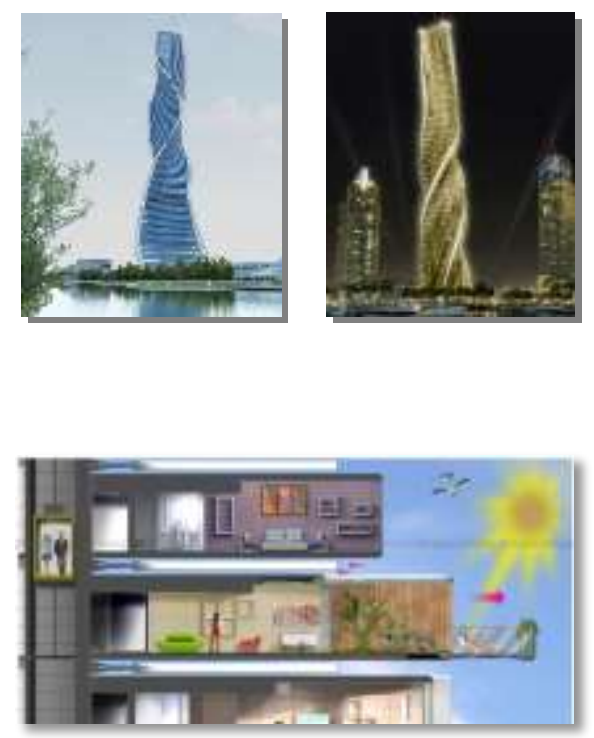

أبرز ميزة للمبنى تكون دوران معظم الطو ابق حول

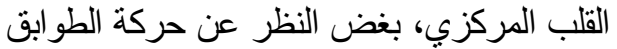

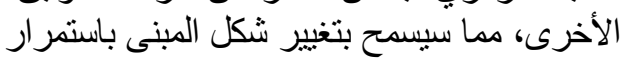
بالبيئة الخار جية وتعدد مطلاته الخار جية.

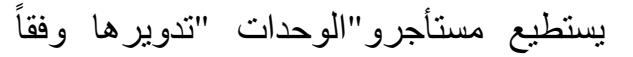
لحركة الشمس من الشروق إلى الثى الغروب، الثاب

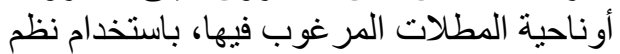
اليكترونية.

خـــامســـــا : العوامل البيئيــــة المكتسبــــة

يوصف " البرج الديناميكي انه مستدام وصديق للبيئة، حيث يتمتع بالقدرة على توليد الكهرباء، ليكون مبنى ذاتي التي لئي

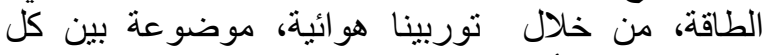

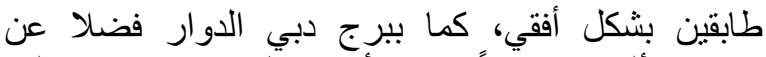

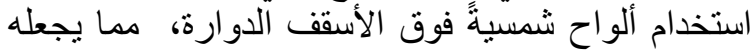

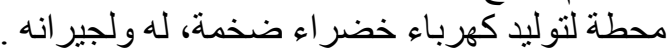

$$
\text { المشروع الثالث : الماته }
$$

أولا: الوصف العام للمشروع: [31]
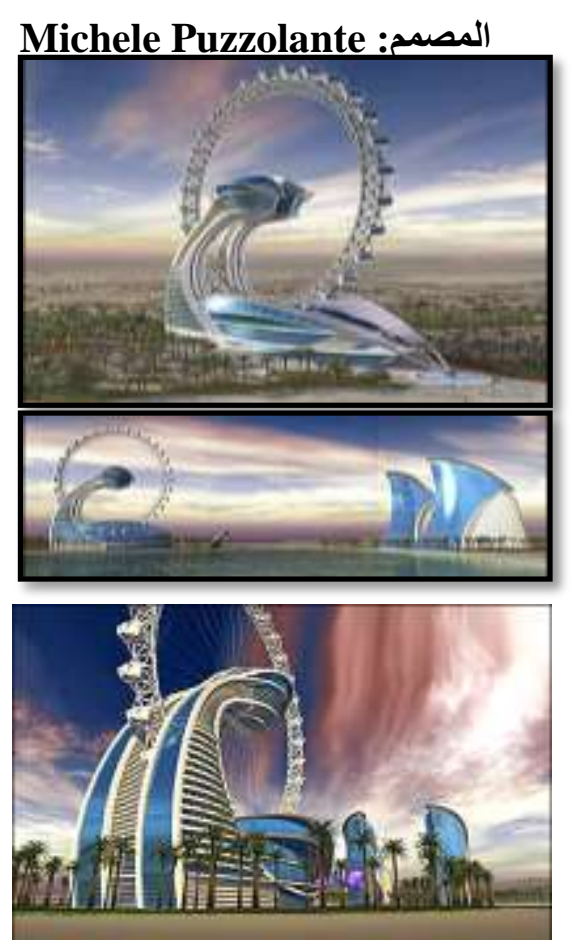

الموقع: أبوظبي ـ الإمارات العربية المتحدة

كل يوم تعيد الإمارات تعريف العمارة الحديثة، فبعد الإماري

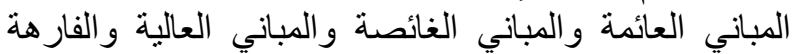

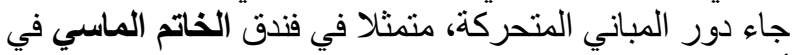

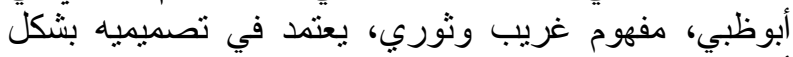
أساسي على فكر الحركة، حيث يعتبر فندق فئ الخاتم الماسي فئي

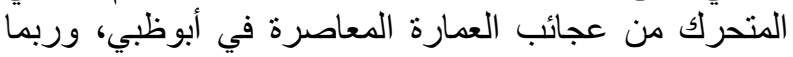

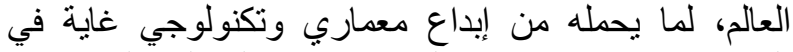

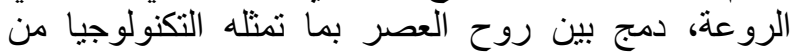

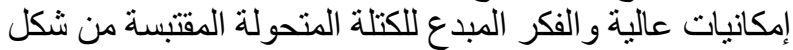

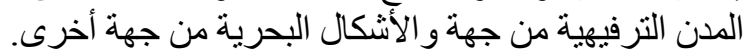

\section{ثانيا: الفكر التصميمي : Design Concept}

فندق الخاتم الماسي تم تصميمه على هيئة الدولاب

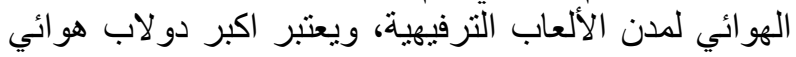

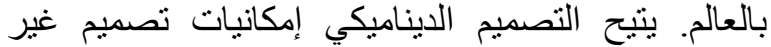

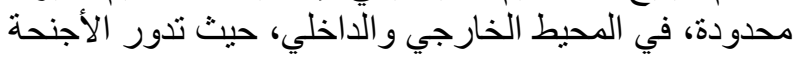

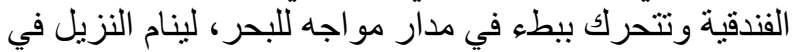


الطابق الأول ويستيقظ في الصباح وهوفي الطابق الثالث

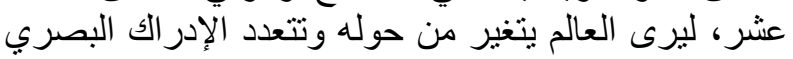

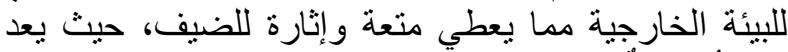
خطوةُ ثوريةٌ في بنائه. مكونات البرج الادوار

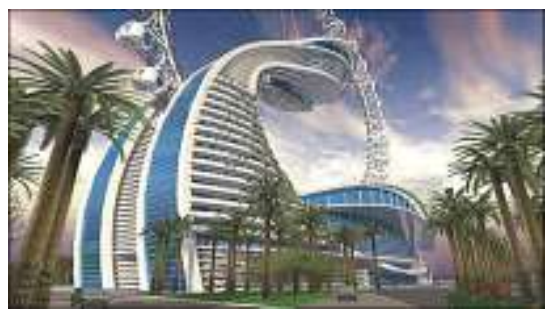

بتكون الفندق من غرف فندقية ثابتة مع كتلة

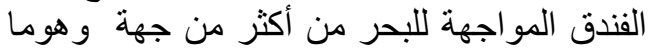
يتميز به الموقع، بالإضافة للأجنحة الفئ الفندقية

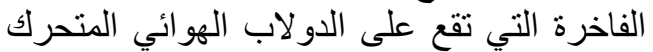

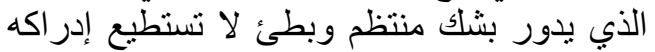

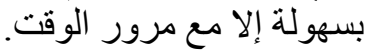
بالإضافة إلي مجمو عة كبير ومتنو عرو الإنة من المطاعم و الخدمات الفندقية و الترفيهية الأخرى.

ثالثا : القيم البيئية والجمالية المكتسبة من حركة المبني :

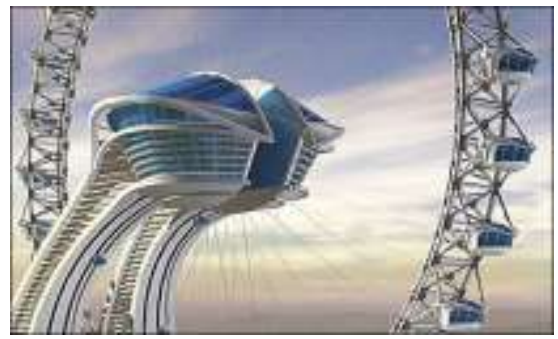

أبرز ميزة للمشروع، تكون في دوران الأجنحة

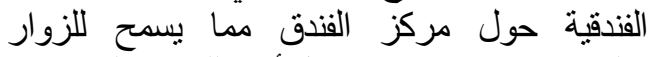
و المريدين بان بستمتعو ا بشكل أكبر للمحيط الخارجي.

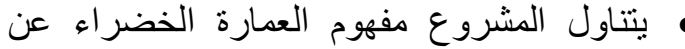

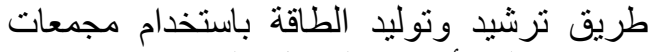

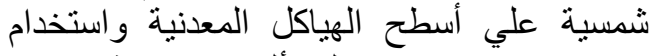

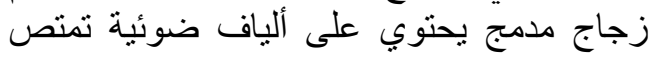

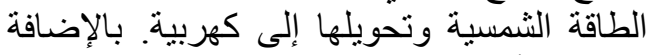
لاستخدام أنظمة للعزل الحرة وتحري.

$$
\text { المشروع الرابع : المابع }
$$

\section{أولا: الوصف العام للمشروع: [32]}

The Poseidon hotel "2008"-اسم المشروع: القندق الغائص المتحرك تحث الماءع Bruce Jones - المصمم: بروس جونز الموقع: كندا - جنوب المحيط الههادي

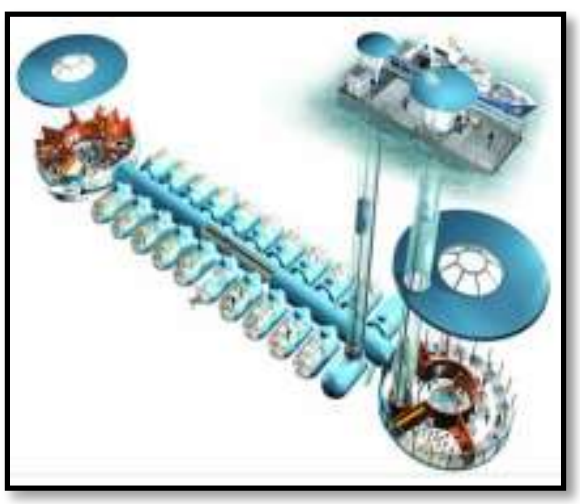

تتنافس جزيرة بوسيدون Poseidon جنوب المباد الميط

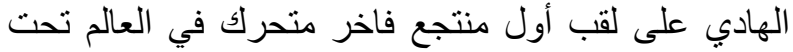

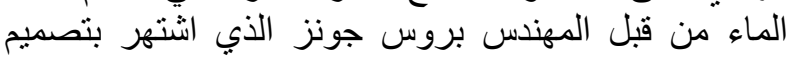

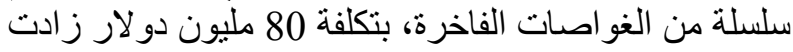

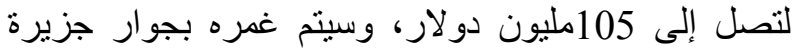

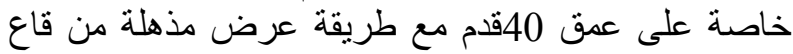

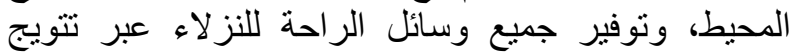

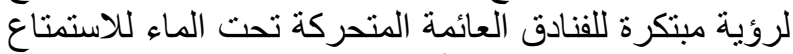

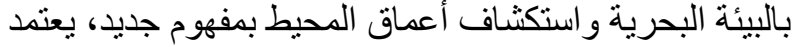

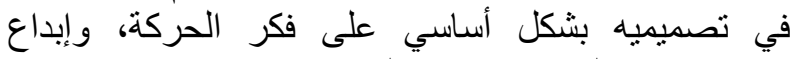
معماري وتكنولوجي غاية في الروعة. 
Design Concept : ثانيا: الفكر التصميمي

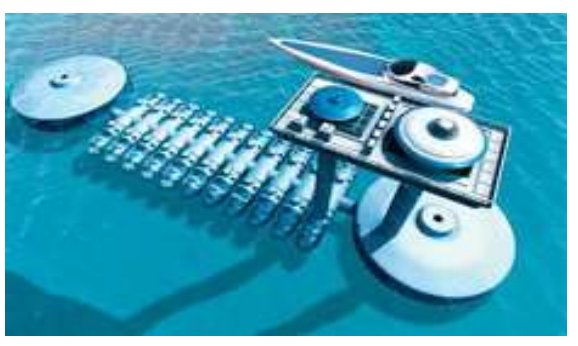

فندق بوسيدون الغامض تم تصميمه ليكون ابتكار بديع الياني

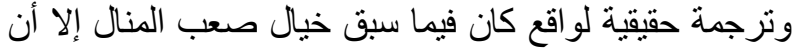

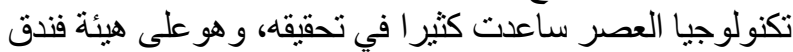
غائص تحت الماء يحتوي على أجنحة فندقية على هلى هيئة

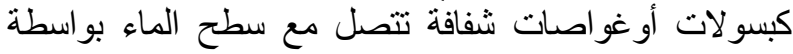

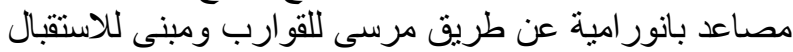

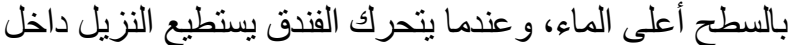
الكبسولة الفندقية رؤية واستكثاف قاع المقاع الفحيط وكائناته الحية.

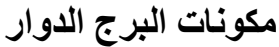
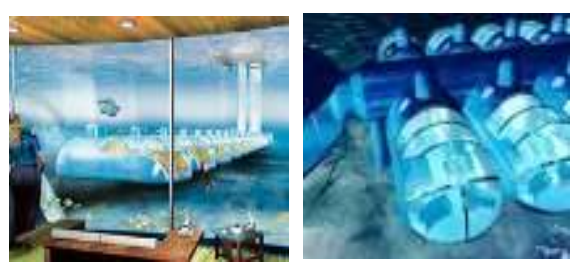

• يتكون الفندق من مرسى للقو ارب وار ومبنى للاستقبال

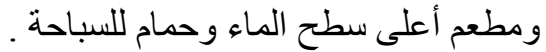
غرف وأجنحة فندقية كبسولية شفافة غائرة تحت المباء الماءو

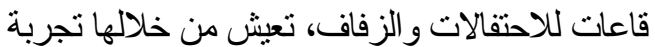
رومانسية رائعة عبر أجو اءو خيالية تحت المحيط

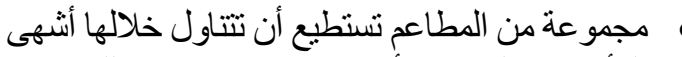
المأكو لات البحرية و أنت تنشاهدها تجوب حولت للك.

ثالثا : القيم البيئية والجمالية المكتسبة من حركة المبني :

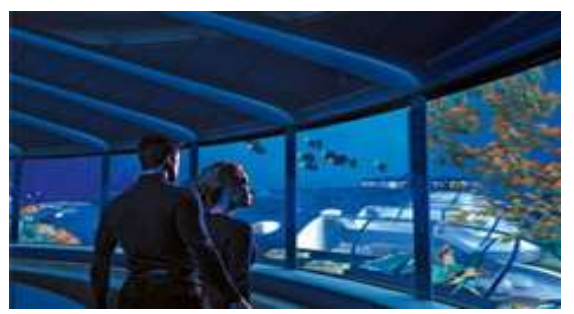

أبرز ميزة للمشروع، تكون في دوران الأجنحة

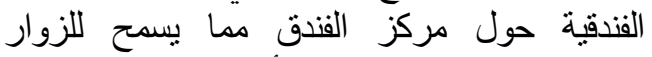
و المريدين بان بيتمتعو ا بشكل أكبر للمحيط الخارجي. يتناول المشروع مفهوم جديد للعمارة والمعايشة المانية مع البيئة و التفاعل معها ورصد هلئه أدق تفاصيلها

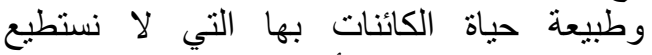

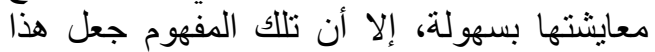

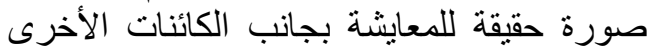
لمشاهدتها بصورة مبانشرة وخيالية.

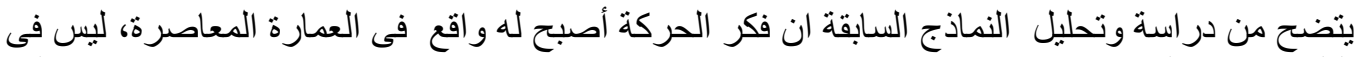

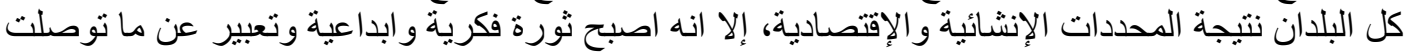

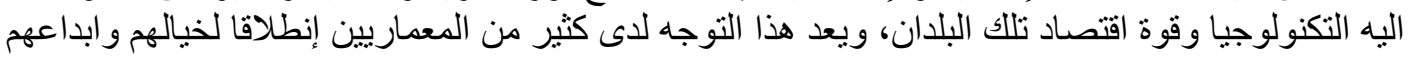

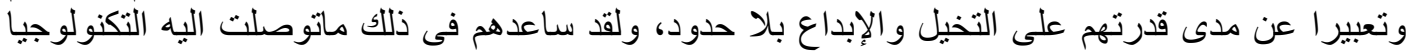

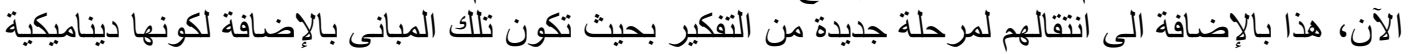

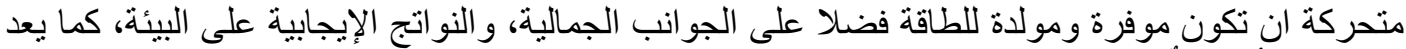

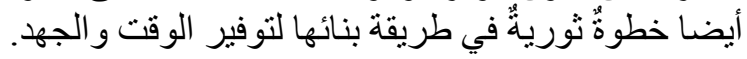

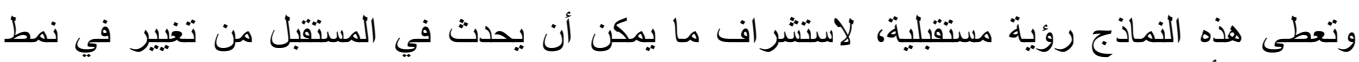

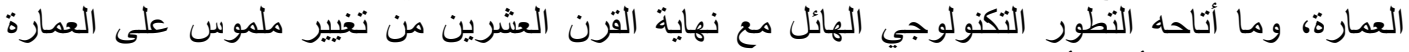

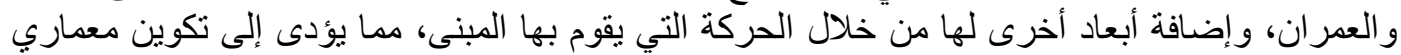

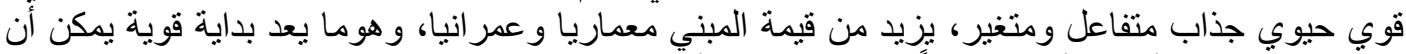

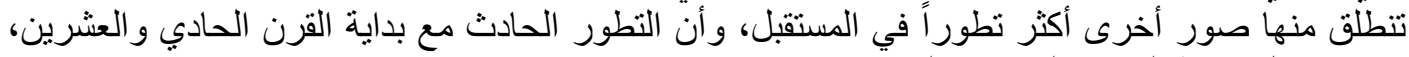




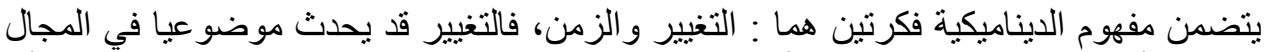

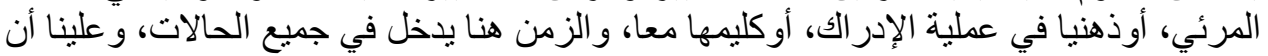

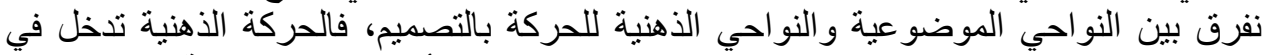

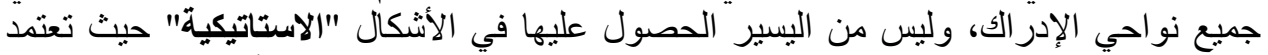

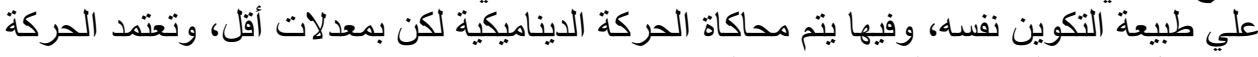
هنا بشكل كبير على قدرة المعماري وخئ وخياله.

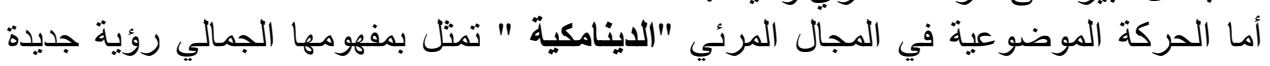

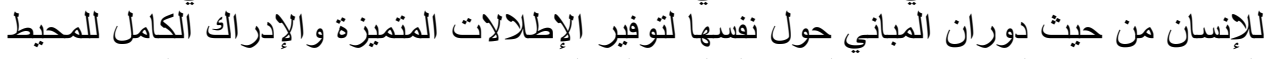

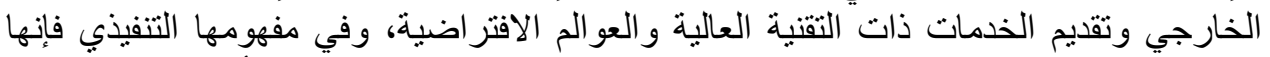

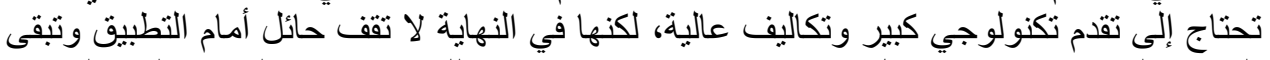

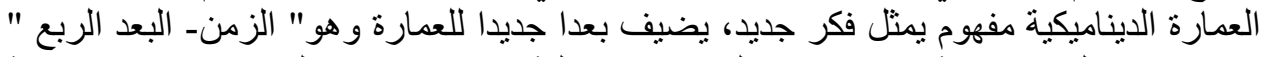

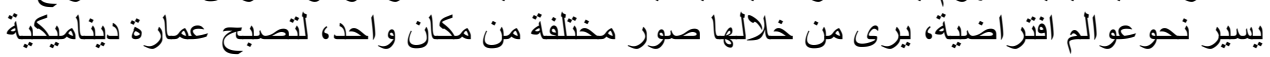
متحركة سماتها التغير في وحدة الزمن.

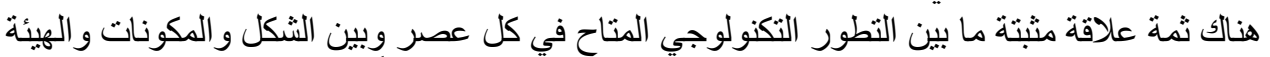

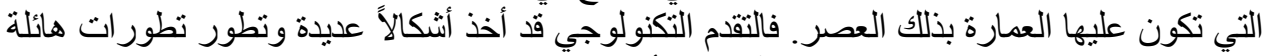

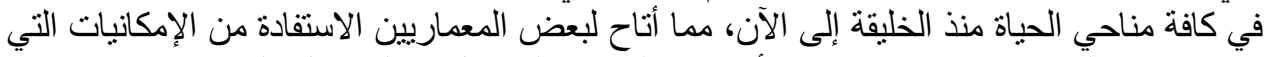

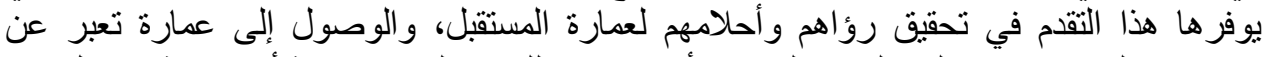

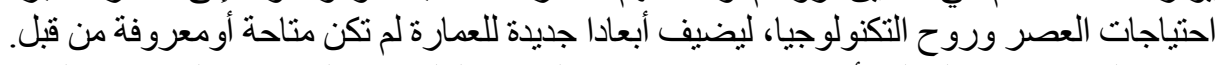

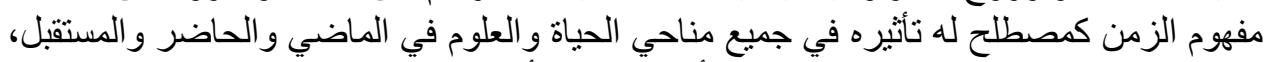

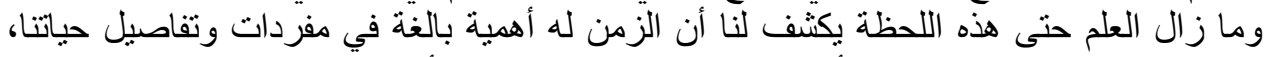

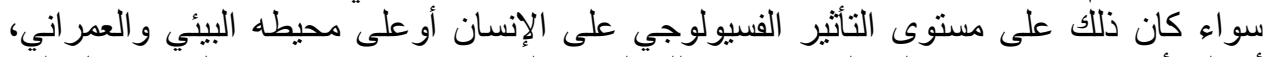

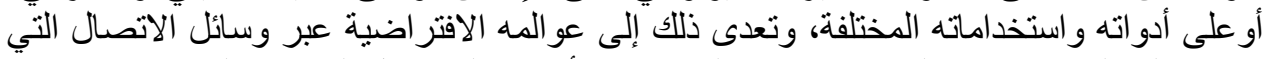

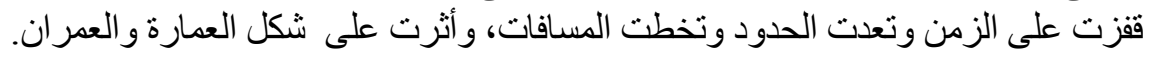

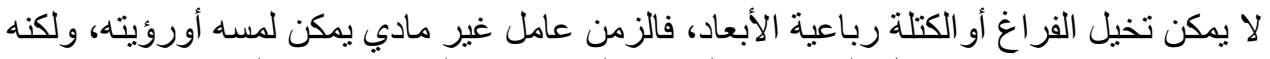

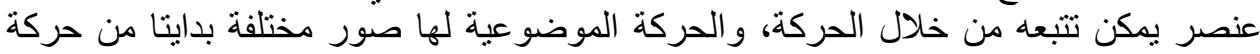

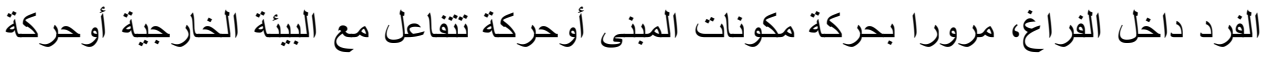

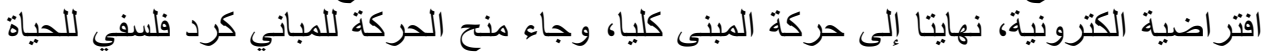

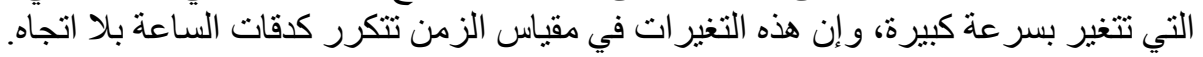

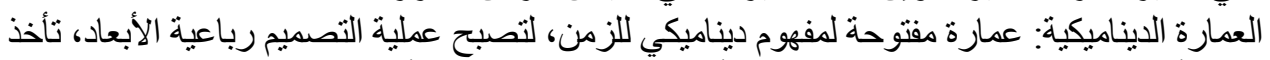

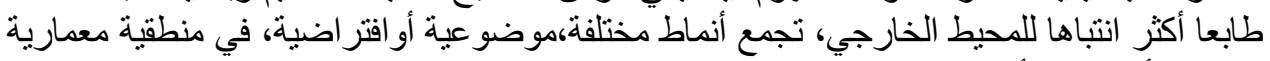

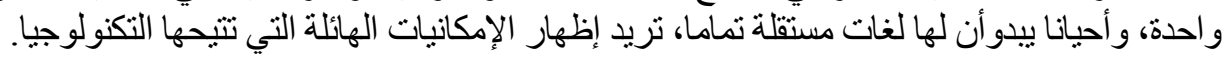

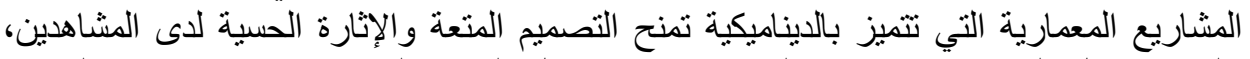

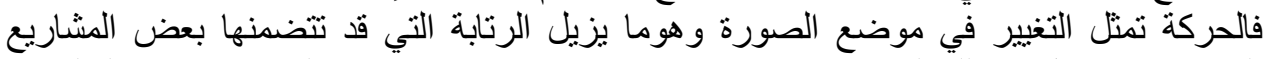

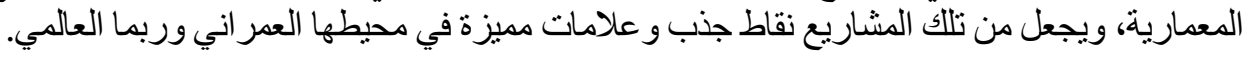

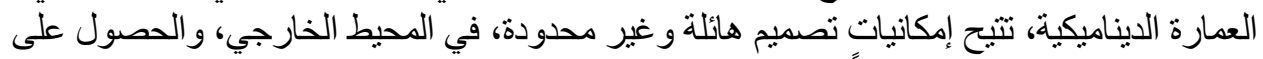

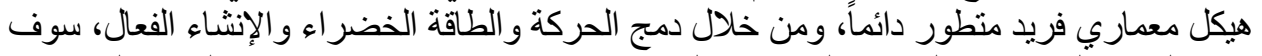

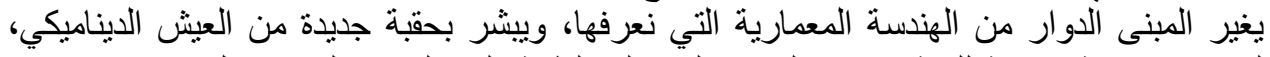

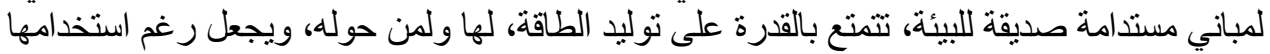

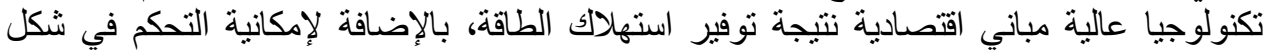

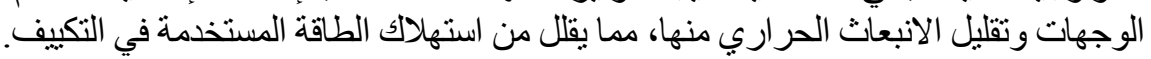




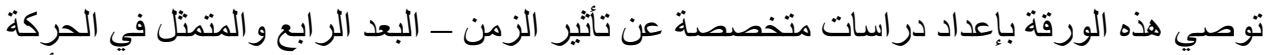

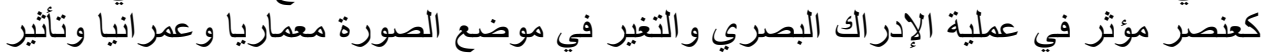

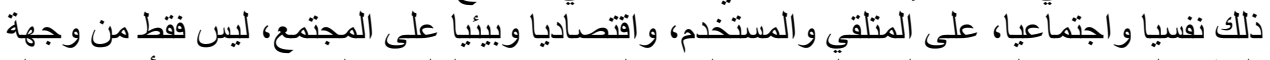

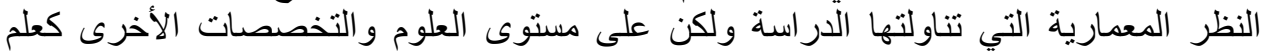

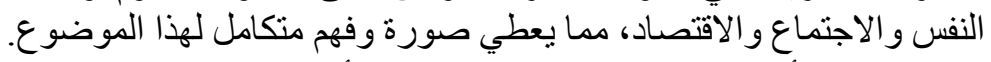

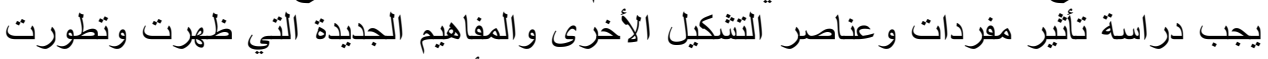

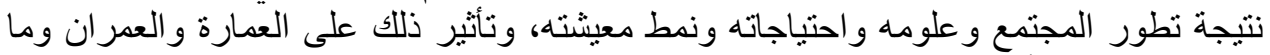

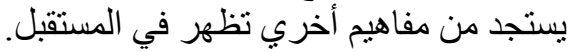

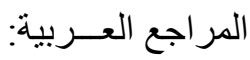

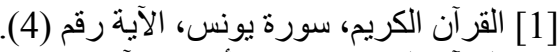

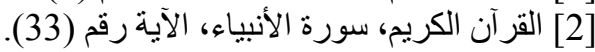
[3] إبراهيم، عبد الباقي "المعماريون العرب-حسن فتحي" النية الناشر- مركز الدراسات التخطيطية والمعماريةـ

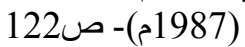

[4] شوارنز، جوزيف وماكينيرز، مايكل."آينشتين للمبندئين" أبوظبي: المجمع الثقافي- بيروت- مؤسسة الانتشار

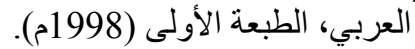

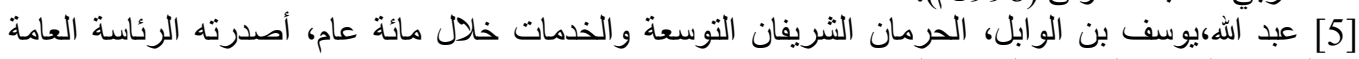

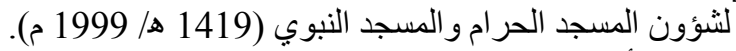

[6] علي رأفت، ثلاثية الإبداع المعماري، دورات الإبداع الفكري، عمارة المستقبل، مركز أبحاث انتركونسلت،

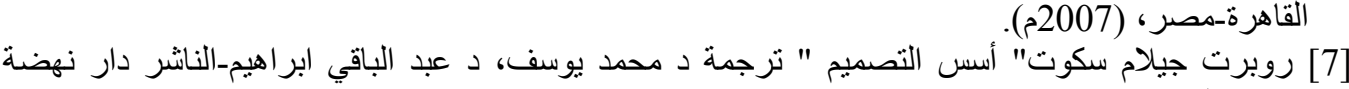

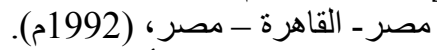

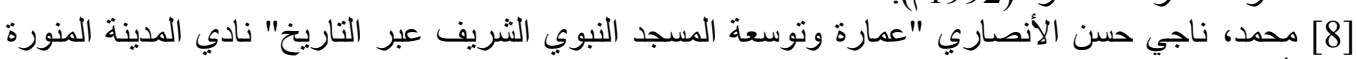

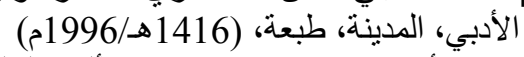
[9] هشام أبوسعده "عمارة وعمر ان الألفية الثالثة من تداعيات الخيال"_الكتاب الأول_الخيال الملكة الغائبةـ الناشر

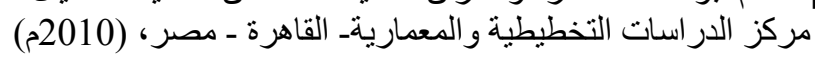

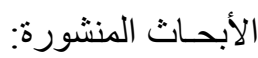

[10] عبد الغني، ألفت سليمان "تطور مفهوم الحركة وانعكاسه على الناتج المعماري، مؤتمر الأزهر الهندسي

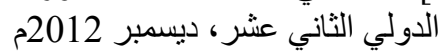

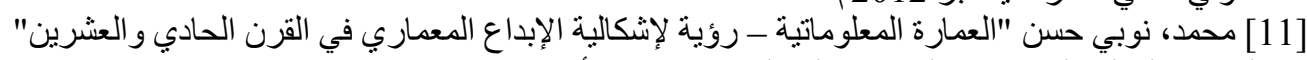

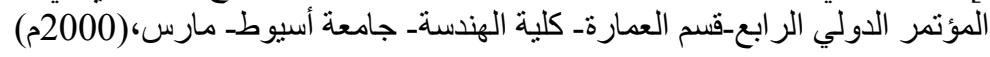

$$
\text { الأبحساث غير المنشورة: }
$$

[12] عبد الحميد، أيمن أمين "أدوات تفعيل بعد الزمن في العملية التصميميةـ در اسة في مسار ات الحركة" قسم

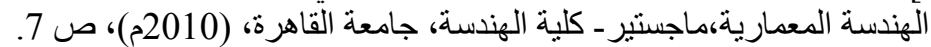

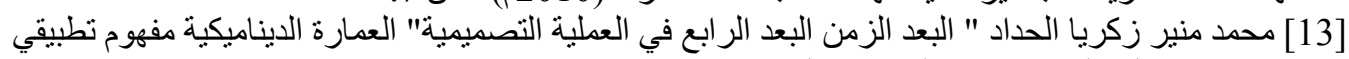

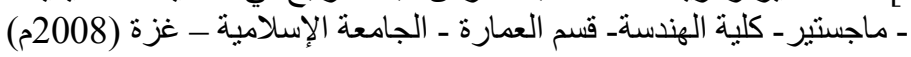

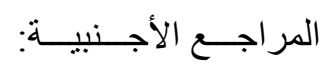

[14] Adeelson, Edward H. "Lightness perception and Lightness Illusions "Massachusetts Institute of Technology, Massachusetts 2004. p1

[15] Andersen, Holly, and Rick Grush، (2005) A.D. "A brief history of time-consciousness: historical precursors to James and Husserl", To appear in the Journal of the History of Philosophy 
أحسد محسمود صـابر محسـد، خصائص وسعات العمارة الدبناميكية ـ البعد الرابع في العمارة ـ الزمن

[16] Jason Bruges: (Jan/Feb 2005)، "Light and Space Explorer"، Architectural Design; -13 4dspace _ interactive architecture، Vol75 No 1. architecturaldesign@wiley.co.uk،Pp.81

[17] Jencks، C.، 2002. The New Paradigm in Architecture. Yale University Press، London.

[18] Fathy, Hassan : (1985) A.D Natural Energy \& Vernacular Architecture. UN University, Tokyo and the University of Chicago، USA.

[19] Lucy Bullivant: (2005, "Media House Project: the House is the Computer، 14the Structure is the Network ", Architectural Design; 4dspace_ interactive, Pp. 57، 58architecturaldesign@wiley.co.ukarchitecture، Vol 75 No 1.

[20] Riewoldt,O: (1997)A.D "Intelligent Space-Architecture for the Information Age" Laurence King Publishing, London، Pp. 7

[21] Schwaller, R. A. de Lubicz Le temple de l'Homme Le Canon Humain، Published by DervyLivres، Paris, (2001) A.D، pp-467-516.

[22] Venturi, R, (1966) AD. Complexity and Contradiction in Architecture. The Museum of Modern Art, New York

[23] Yolande Harris Riversdale: (2000) AD، "From Moving the Imge to Moving Architecture- A discussion of the "Space-Time" phenomenon of the twentieth century, with particular reference to architecture, moving img, and music. "Grant Chester Cambridge England, Pp. 2

[24] Zewail ' Ahmed: Voyage Thruogh Time-Walks of Life to the Nobel Prize" The American University in Cairo Press, World Scintific Publishing Co. PTE. Ltd, Pp. 122

[25] Zellner, P., (1999) AD Hybrid Space. New Forms in Digital Architecture. Thames and Hudson Ltd, London, Pp.76

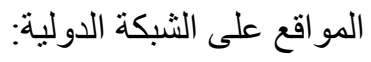

[26] http://ar.wikipedia.org/wiki

[27] http://www.archdaily.com/.../kiefer-technic-showroom...

[28] http://www.arch-news.net/

[29] http://www.dynamicarchitecture.net/

[30] www.worldbuildingsdirectory.com/index.cfm.( Giselbrecht، Ernst‘2013)

[31] http://www.bornrich.com/worlds-top-10-futuristic-luxury-hotels.html

[32] http://weburbanist.com/2007/11/24/sink-or-swim-5-submerged-and-floating-seaworthyhotels-for-the-adventurous-urbanite/

[33] http://ar.wikipedia.org:Cairo،_Tower_of_Cairo_Egypt‘_Oct_2004.jpg

[34] http://www.emporis.com/building/suitevollard-curitiba-brazil

[35] http://www.home-designing.com/2010/06/space-saving-apartment

[36] http://www.amana-md.gov.sa

[37] http://www.3marah.com/vb/showthread.php?t=1434

[38] http://www.falkirk-wheel.com/

[39] http://www.blogger.com.

[40] http://www.january-25.org/post.aspx?k=76179 


\title{
CHARACTERISTICS AND FEATURES OF THE DYNAMIC ARCHITECTURE THE FOURTH DIMENTION IN THE ARCHITECTURE - TIME
}

\begin{abstract}
This paper examines the concept of dynamic architecture - the fourth dimension "TIME" as a new concept in the contemporary architecture، where the movement happens in the design, either objectively in the visual field, or mentally in the process of cognition, where producing the mental movement "static" of the order of the design elements sequentially, by simulating the dynamic movement but at rates less, It depends on the ability and imagination of the architect on the composition kinetic to the mass, The objectivity movement "dynamic" taken it the many of architects partial ways in the past by dealing with degrees of the technological advances by then, out that appeared in this century more advanced, which allowed for some architects to achieve their visions and their dreams for the future architecture, it represents a new vision of the aesthetic concept of the human' in terms of rotation of the buildings around itself to provide the panoramic views and fully perception of the outside to enjoy the environment, to become a dynamic moving architecture features it change in time per unit, to give a new aesthetic dimension to architecture, it is the fourth dimension in the design process," time". And it is raising quality of the architectural design and strength space it, in addition to being distinctive building inside the urban surroundings ، which aims search and is a strong start for other images more advanced in the future.
\end{abstract}

Keywords: (Dynamic Architecture - The movement in design- The Movement thought - Smart architecture - The fourth dimension "Time".) 